\title{
Fragility Curves for Non-Ductile Reinforced Concrete Frames that Exhibit Different Component Response Mechanisms
}

Jong-Su Jeon (Corresponding author): Post-Doctoral Researcher, School of Civil and Environmental Engineering, Georgia Institute of Technology, Atlanta, GA 30332, USA

Phone number: +1-404-895-5241; Fax number: +1-404-894-2278;

Email: jongsu.jeon@gatech.edu

Laura N. Lowes: Associate Professor, Department of Civil and Environmental Engineering, University of Washington, Seattle, WA 98195, USA

Phone number: +1-206-685-2563; Fax number: +1-206-543-1543;

Email: lowes@u.washington.edu

Reginald DesRoches: Karen and John Huff School Chair and Professor, School of Civil and Environmental Engineering, Georgia Institute of Technology, Atlanta, GA 30332, USA

Phone number: +1-404-894-2201; Fax number: +1-404-894-2278;

Email: reginald.desroches@ce.gatech.edu

Ioannis Brilakis: Laing O'Rourke Lecturer in Construction Engineering, Department of Engineering, University of Cambridge, Cambridge, CB2 1PZ, UK

Phone number: +44-(0)-1223-332718; Fax number: +44-1223-3-32662;

Email: ib340@eng.cam.ac.uk 


\begin{abstract}
Around the world, a large percentage of buildings in regions of high seismicity are older, nonductile reinforced concrete. To assess the risk posed by these buildings, fragility functions are required to define the likelihood that these buildings will sustain damage and collapse under earthquake loading. This paper presents the initial phase of a research effort to develop fragility functions for non-ductile concrete frames using numerical simulation; the research presented in this paper focuses on development of the numerical model and application of the model to develop fragility functions for a prototype non-ductile concrete frame. To enable numerical simulation of concrete frame buildings, response models for beam-column joints and columns are developed to provide (1) appropriate simulation of component response and, thereby, reliable assessment of risk and (2) computational efficiency and robustness. These new models are developed using existing experimental data, build on response models proposed by others, and employ component and material models available in the OpenSees analysis platform (http://opensees.berkeley.edu). A new beam-column joint model combines a new expression for joint strength and newly developed cyclic response parameters; a new column response model includes a new shear-strength model and newly developed cyclic response parameters. Numerical models of a prototype non-ductile concrete frame are developed that include simulation of one or more of the following characteristics: (1) rigid beam-column joint, (2) nonlinear joint shear response, (3) nonlinear joint shear and bond-slip response, and (4) column shear failure. Dynamic analyses are performed using these frame models and a suite of ground motions; analysis results are used to develop fragility curves. Fragility curves quantify the vulnerability of the frame and provide understanding of the impact of different component failure mechanisms on frame vulnerability.
\end{abstract}

Keywords: non-ductile reinforced concrete frames; failure modes; column shear model; beamcolumn joint model; fragility analysis. 


\title{
Fragility Curves for Non-Ductile Reinforced Concrete Frames that Exhibit Different
}

\section{Component Response Mechanisms}

\author{
Jong-Su Jeon $^{1 *}$, Laura N. Lowes ${ }^{2}$, Reginald DesRoches ${ }^{3}$, Ioannis Brilakis ${ }^{4}$
}

\section{Introduction}

Historical seismic events (Northridge 1994, Kobe 1995, Kocaeli 1999) have demonstrated that older reinforced concrete (RC) buildings designed only for gravity loads may exhibit severe damage and collapse under moderate to severe earthquake demands [1-3]. For these structures, inadequate detailing typically includes insufficient transverse reinforcement in columns, column lap splices in potential plastic-hinge regions, lack of joint transverse reinforcement, and inadequate anchorage of beam longitudinal reinforcement in joints. Inadequate detailing of beam-column joints and columns is particularly critical as it can result in premature loss of lateral and axial load-carrying capacity for individual components and thereby lead to premature collapse of the building. Building inventories across the country include a large number of these older concrete buildings that are vulnerable to collapse under earthquake loading. Fragility functions defining the likelihood of reaching stipulated damage states (building performance levels) as a function of earthquake intensity represent a simple, fast tool for preliminary assessment of the risk posed by these buildings. Fragility functions can be generated using numerical models of buildings with a range of configurations and design details; however, reliable assessment of seismic risk requires appropriate simulation of component failure mechanisms.

To date, relatively few studies have addressed the development of fragility functions for older concrete buildings using models that simulate the range of response mechanisms expected 
to control the earthquake behavior of these structures. Celik and Ellingwood [4] and Jeon et al. [5] developed fragility curves for non-ductile RC frames in low and moderate seismic zones for which joint failure was assumed to control frame response. Frames were designed only for gravity loads in accordance with ACI 318-89 [6], and numerical models simulated the nonlinear flexural response of beams and columns as well as non-ductile shear failure of beam-column joints. Liel [7] and Baradaran Shoraka [8] developed fragility curves for collapse for older RC frames in high seismic zones. Frames were designed using the equivalent lateral load procedure in accordance with the 1967 Uniform Building Code [9]. Numerical models simulated beamcolumn joint and column shear failure, beam and column flexural failure, and loss of column axial load carrying capacity. Both Liel [7] and Baradaran Shoraka [8] concluded that frame collapse resulted from columns losing lateral and, ultimately, axial load carrying capacity due to shear failure and that joint shear failure typically did not occur. While the models employed in the studies $[7,8]$ defined column shear strength on the basis of column design parameters, generic joint response models were employed. Thus, potential for joint-controlled system response was not accurately assessed in these studies.

In addition to employing different frame designs and numerical models, the above studies also employed different probabilistic assessment tools to generate fragilities. Celik and Ellingwood [4] and Jeon et al. [5] develop fragility curves for multiple performance levels (immediate occupancy, life safety, and collapse prevention) using the cloud method in which unscaled ground motions representative of the seismic hazard region of interest are used for dynamic analyses. Liel [7] and Baradaran Shoraka [8] developed fragility curves for system collapse using a scaling approach, in which dynamic analyses are performed using a suite of ground motions scaled to increasing intensity levels and the collapse intensity is defined as that 
which results in more than $50 \%$ of the motions resulting in excessive story drifts and global dynamic instability of the structure. Baker and Cornell [10] notes that the scaling approach may result in unrealistically large ground motions that are not representative of the earthquake hazard in a region while the cloud method has the advantage of being compatible with a closed form solution. The cloud method is also more effective for investigating the influence of component response on the probability of observing multiple damage states.

The primary goals of the research presented here are to (1) propose models for nonductile RC joints and columns that simulate the primary earthquake response characteristics of these components and can be easily implemented in OpenSees [11] using existing element and material models and (2) use these models to assess the earthquake vulnerability of existing RC buildings and the impact of component response on this vulnerability. Component models such as beam-column joint and column shear are developed and validated using existing experimental results and are employed to simulate the earthquake response of an idealized 2D concrete frame with design details typical of older (pre-1967) construction. Five models of the frame are considered; these models include simulation of (1) rigid joint response and flexure-controlled column response, (2) joint shear stress-strain response, (3) joint shear response and anchorage failure for beam reinforcement embedded in the joint, (4) column shear, and (5) joint and column shear response. Earthquake performance as predicted using the five models is compared and corresponding failure probabilities across various limit states are computed to examine the relative vulnerability of frames. The results of this study provide a basis for further work to develop fragility functions for older buildings and after-shock fragilities for concrete frame buildings [12]. 


\section{Non-ductile joint and column shear response mechanisms}

Due to the lack of ductile detailing in older RC building frames, frame response may be controlled by (i) flexural yielding of beams or columns, (ii) shear failure of beams or columns, or (iii) joint failure due to shear or anchorage. There is consensus within the earthquake engineering community that flexural yielding and premature flexural failure resulting from inadequate confinement of concrete can be simulated using the basic fiber-type beam-column elements and material models available in OpenSees [11]. For most frame configurations, beam shear demands are low and thus shear failure is unlikely to occur. Thus, remaining failure modes are joint response and column shear response. Consensus does not exist within the community as to the best models for use in simulating these response mechanisms.

Joints in older frames typically exhibit three failure modes: (1) joint shear failure prior to beam or column yielding, which typically results in rapid loss of strength and stiffness with increasing deformation demand, (2) joint shear failure after beam yielding, which typically results in more gradual strength loss and moderately ductile behavior, and (3) anchorage failure (i.e. pullout) of beam bottom reinforcement prior to beam yielding, resulting from a short embedment length for beam reinforcement anchored within the joint. Columns in older frames may exhibit limited ductility due to flexural or shear failure; for either of these failure modes, failure initially results in loss of lateral load carrying capacity and ultimately leads to loss of axial load carrying capacity. Typically column shear failure is categorized as occurring (1) prior to significant flexural yield and resulting either from sudden propagation of one or more critical diagonal cracks (tension) or from crushing or diagonal splitting of concrete (compression) or (2) following significant flexural yielding and resulting from deterioration of shear capacity in the flexural-hinge region of the column. 
Previous research has resulted in numerical models that simulate joint and column response as controlled by the failure modes described above. However, for application in the current study, component models are needed that meet the following requirements: (1) simulation of the cyclic response of components with inadequate detailing typical of older construction, this includes including simulation of the onset of failure at low demands, limited ductility, and relatively rapid strength loss, (2) is validated using a large experimental dataset, (3) can be implemented in OpenSees using existing element formulations and material models, and (4) provides the numerical efficiency and robustness required for generation of fragility functions [13].

\section{Proposed non-ductile beam-column joint model}

This section addresses the modeling of interior joints exhibiting joint shear failure and exterior joints exhibiting joint shear or anchorage failure, including (i) a general explanation of the response envelope, (ii) determination of joint strength, and (iii) calibration of other envelope and cyclic response parameters. A new beam-column joint model was developed; this model consists of a new joint moment-rotation relationship for use with a rotational hinge element. The model is developed using an extensive existing experimental dataset, builds on response models proposed by others, and employs existing OpenSees component and material models. Joint shear strength is a function of joint configuration (external T-joint versus internal cruciform as well as joints with and without transverse beams), material properties, geometry, and design characteristics. Additional key parameters defining the response envelope and behavior under cyclic loading are determined to provide a least-squares best-fit to load-drift data for joint subassemblages tested in the laboratory. Joint moment-rotation response is determined from the experimental joint shear 
stress-strain relationship. Simulated and measured response histories are compared to verify the model.

\subsection{Analytical model of non-conforming beam-column joints}

Fig. 1 shows the numerical model of a beam-column joint assemblage used in laboratory tests; this was used for development and validation of the beam-column joint model. Columns were modeled using elastic beam-column elements away from the beam-column joint region and the OpenSees displacement-based nonlinear beam-column element with five integration points in the plastic hinge region(s); beams were modeled using the OpenSees beamWithHinges element. For both members, the plastic hinge length $\left(L_{p}\right)$ was taken equal to half the section depth [14]. For the fiber sections, confined and unconfined concrete were modeled using the OpenSees Concrete02 material model, which includes simulation of concrete tensile strength. The confinement of concrete due to transverse reinforcement was determined using the model of Mander et al. [15]. Longitudinal reinforcement was modeled using the OpenSees Hysteretic material model, with an assumed hardening ratio of 0.01 . For specimens with slabs, the slab was modeled as the unconfined concrete material model and its effective width was calculated following the recommendation of ACI 318-11 [16]. The stiffness of elastic sections in columns and beams was calculated based on the elastic modulus of concrete and the cross-section.

Fig. 1. Analytical model of beam-column joint subassemblage.

The response envelope for the new joint model is shown in Fig. 2; this envelope incorporates aspects of the Anderson et al. [17] and Kim and LaFave [18] models. The initial two 
segments of the envelope are taken from Anderson et al. [17], with the exception that while Anderson et al. [17] defines joint strength $\left(\tau_{\max }\right)$ on the basis of beam flexural strength and joint geometry, here an expression for joint shear strength is developed. Similar to the work of Kim and LaFave [18], this expression for maximum joint shear strength is developed using an experimental dataset and joint shear strength is defined as a function of multiple beam and joint design parameters. In the model by Anderson et al. [17], the remainder of the response envelope is defined by the load history. Here, to enable the use of existing OpenSees Pinching4 material model, joint shear strain corresponding to maximum joint shear stress $\left(\gamma_{3}\right)$ and post-peak stiffness $\left(k_{\mathrm{deg}}\right)$ in Fig. 2 are defined to provide a best fit to the experimental data. A residual strength equal to $20 \%$ of the maximum joint shear strength is assumed by extrapolating the third and fourth points of the envelope curve.

Fig. 2. Envelope of joint shear stress-strain relationship.

The joint region is modeled using a two-node, zero-length rotational joint spring and four rigid offsets [19], as shown in Fig. 1. Joint response is simulated using a material model that defines joint moment versus rotation. As provided in Celik and Ellingwood [20], the joint rotational moment-rotation relationship is determined from the joint shear stress-strain relationship using equilibrium and compatibility:

$$
M_{j}=\frac{\tau_{j} A_{j}}{\left(1-h_{c} / L_{b}\right) / j d_{b}-\eta / L_{c}}, \quad \theta_{j}=\gamma_{j}
$$

where $M_{j}=$ joint rotational moment, $\tau_{j}=$ joint shear stress; $h_{c}=$ depth of the column; $A_{j}=$ joint area $\left(h_{c} \cdot b_{j}\right) ; b_{j}=$ effective width of the joint panel calculated from ACI 352R-02 [21]; $L_{b}=$ total length of the left and right beams; $L_{c}=$ total length of the top and bottom columns; $j=$ internal 
moment arm factor (assumed to be 0.875 ); $d_{b}=$ effective depth of the beam; $\eta=2$ and 1 for the top floor joints and others, respectively; $\theta_{j}=$ joint rotation; and $\gamma_{j}=$ joint shear strain.

\subsection{Joint shear strength models for non-ductile joints exhibiting shear and anchorage failure}

\section{$\underline{\text { 3.2.1 Shear strength model for joints exhibiting shear failure }}$}

The response envelope shown in Fig. 2 is defined by the maximum joint shear strength $\left(\tau_{\max }\right)$. Kim and LaFave [18] employs a stepwise removal process in combination with the Bayesian updating method to find a reduced set of variables that define joint shear strength. This purely empirical approach can capture the enhancement of joint shear strength resulting from $3 \mathrm{D}$ effects that is not easily incorporated in mechanics-based models. However, non-conforming joints were not the focus of the Kim and LaFave effort, and the dataset used by Kim and LaFave [18] includes a limited number of non-conforming joints. Due to this limitation, the current study developed a new joint strength model for non-ductile joints using a forward step-wise multiple linear regression (MLR) method and an extensive experimental dataset. The dataset comprised 168 interior (cruciform) and 93 exterior (T-shaped) beam-column joint subassemblages with and without out-of-plane beams. Table 1 provides statistics (minimum, maximum, mean, and coefficient of variation (COV)) for the dataset for critical design parameters. All specimens in the dataset have joint transverse reinforcement spaced at half the column depth or greater; thus, all specimens are "non-conforming" joints as defined by ASCE 41-06 [22]. The specimens in the dataset exhibited joint failure either prior to or following beam or column yielding in flexure. Additional information about the dataset is provided in Jeon [12] and Jeon et al. [13].

Table 1 Summary of complete experimental dataset. 
Using the candidate predictor variables employed by Kim and LaFave [18], a forward stepwise MLR approach was employed, in a log-transformed space, to search for significant predictor variables. Using this approach, predictor variables are sequentially added to the model and their significance is evaluated using analysis of variance testing until no significant terms are left. The result was a new joint strength model for non-conforming joints:

$$
\tau_{\max }=-0.586(T B)^{0.774}(B I)^{0.495}(J P)^{1.25}\left(f_{c}\right)^{0.941}
$$

where $\tau_{\max }=$ maximum joint shear stress in $\mathrm{MPa} ; B I=$ beam reinforcement index, which is defined as the product of the beam longitudinal reinforcement ratio and the beam longitudinal reinforcement yield stress divided by the beam concrete compressive strength (averaging quantities for top and bottom reinforcement); $J P=$ parameter for describing in-plane geometry (1 for interior and 0.75 for exterior joints); $T B=$ joint confinement factor $(1.0$ for subassemblages with 0 or 1 transverse beam and 1.2 for subassemblages with 2 transverse beams), and $f_{c}=$ joint concrete compressive strength in MPa.

Fig. 3 shows joint shear strength computed using Eq. (2) compared with experimental joint shear strengths. The coefficient of determination for the model is 0.858 ; the mean and COV of the ratio of computed-to-experimental joint shear strength are 1.011 and 0.148 , respectively. Thus, the proposed joint shear strength model for non-conforming joints provides a relatively high level of accuracy and precision. Additional information about the model development and evaluation process is presented in Jeon [12].

Fig. 3. Comparison of computed and experimental joint shear strength. 


\subsubsection{Shear strength model for joints exhibiting anchorage failure}

This section describes the calculation of joint shear strength $\left(\tau_{\max }\right.$ as defined in Fig. 2$)$ for exterior joints in which beam longitudinal reinforcement terminates in the joint with a short embedment length. To simulate this failure mechanism, the joint strength model developed by Hassan [23] was used. The Hassan model was derived using an empirically-based bond strength model, a load transfer model for the joint that assumes anchorage failure prior to beam rebar yielding, and Eq. (1). Hassan [23] defines only joint strength and does not define joint loaddeformation response. Here, a moment-rotation response model was developed and implemented using the OpenSees Pinching4 material; the development process was similar to that used for interior joints.

The equivalent shear strength model associated with short embedment of beam bottom longitudinal reinforcement in joints can be expressed using equilibrium of the subassemblage:

$$
\tau_{\max }=\frac{T_{s}}{A_{j}}\left[1-\frac{\left(1+0.5 h_{c} / l_{b}\right) j d_{b}}{L_{c}}\right]
$$

where

$$
T_{s}=n_{b} l_{s p} \pi \phi_{b} \tau_{\text {bond }}
$$

and $T_{s}$ is the maximum tension force developed in the poorly anchored beam bottom reinforcement, $l_{b}$ is the beam length measured from the face of column to the end of beam, $n_{b}$ is the number of beam bottom longitudinal rebars, $l_{s p}$ is the embedment length within a joint, $\phi_{b}$ is the diameter of the beam bottom longitudinal rebars, $\tau_{\text {bond }}$ is the maximum average bond strength developed by Hassan [23]:

$$
\tau_{\text {bond }}=1.1\left(\frac{P}{f_{c} A_{g}}\right)^{0.25} \sqrt{f_{c}} \Psi_{s} \Omega \frac{c}{\phi_{b}}
$$


where $P=$ column axial load; $\Psi_{s}=$ reinforcement factor $\left(\Psi_{s}=1\right.$ for $\phi_{b} \geq 19 \mathrm{~mm}$ and $\Psi_{s}=1.25$ for $\left.\phi_{b}<19 \mathrm{~mm}\right) ; \Omega=$ transverse beam confinement factor $(\Omega=1,1.12,1.20$ for exterior joints without and with one and two transverse beam(s), respectively); $c=$ minimum of bottom and side concrete cover; $A_{g}$ is the column area. Hassan [23] demonstrates that the model is well-correlated with 21 exterior joints in that the mean and $\mathrm{COV}$ of the predicted-to-experimental shear strength ratio are 1.099 and 0.161 , respectively.

ACI Com. 352 [21] defines joint shear demand on the basis of the tension and compression forces that can be developed by beam longitudinal reinforcement framing into the joint. For the exterior joint considered here, joint shear demand is limited by the tension force $\left(T_{s}\right)$ that can be developed in beam bottom reinforcement. While Eq. (3) is derived using the ACI Com. 352 recommendation for defining joint shear demand, $\tau_{\max }$ defined in Eq. (3) may be considered to represent maximum joint shear capacity of the exterior joint subassemblage as limited by $T_{s}$. When the beam bottom reinforcement is in tension (anchorage failure), the joint shear strength was computed by Eq. (3), while when beam bottom reinforcement was in compression, strength was determined by Eq. (2).

\subsection{Response envelope and cyclic response parameters}

Beam-column joint response was simulated using the OpenSees Pinching4 material model. This model includes a multi-linear response envelope as shown in Fig. 2 and a tri-linear unload-reload path as shown in Fig. 1. The above sections address definition of critical points on the response envelope; this section addresses empirical calibration of the remainder of the response envelope $\left(\gamma_{3}\right.$, and $k_{\mathrm{deg}}$ as shown in Fig. 1) and cyclic response parameters. For this purpose, a subset of the specimens in Table 1 was used for this calibration effort. This reduced dataset comprised 23 exterior and 35 interior joints exhibiting joint shear failure and five exterior joint specimens 
exhibiting anchorage failure. For each test included in the calibration effort it was necessary to digitize the experimental load-displacement history, create an OpenSees model of the test specimen, and perform a parameter study to determine the model parameters providing a best-fit to the data. Thus, a reduced dataset was used for the calibration because, for many tests, highquality digitized load-displacement histories could not be generated or data required for creation of the OpenSees model were not provided. For each specimen, response envelope and cyclic response parameters were determined to provide a least-squares best-fit to the experimental loaddisplacement history. Average values of these parameters are listed in Table 2. Note that although the Pinching4 material model includes simulation of deterioration of strength and stiffness as a function of deformation demand and energy dissipation, calibration results $\left(\alpha_{*_{2}}=\right.$ $\alpha_{* 4}=0$ ) indicate that a deformation-based model was adequate for response simulation. Here, $\alpha *$ 's are the parameters required in fitting the damage rule to experimental data.

Table 2 Recommended modeling parameters of Pinching4 material.

\subsection{Bar-slip associated with column and beam longitudinal rebars}

Zero-length bar-slip fiber-section elements are located at the ends of the column to simulate flexibility associated with bar-slip out of the joint [24-26]. As shown in Fig. 1, to account for the additional rotation due to the effect of bar-slip at the end of members, a fiber-type model of the column section is created in which fiber response is defined by stress-displacement relationships. In this case, the section model defines moment versus rotation and axial load versus axial elongation responses. To capture this behavior, the current study employed the relation between reinforcing steel strain and slip presented by Sezen [27]: 


$$
\begin{aligned}
& \operatorname{slip}_{y}=\frac{\varepsilon_{y} f_{y} \phi_{c}}{8 u_{e}} \\
& S F_{\text {slip }}=\frac{\operatorname{slip}_{y}}{\varepsilon_{y}}
\end{aligned}
$$

where slip $_{y}=$ bar slip at yield $(\mathrm{mm}), \varepsilon_{y}=$ longitudinal reinforcement yield strain, $f_{y}=$ longitudinal reinforcement yield stress (MPa), $\phi_{c}=$ diameter of column longitudinal reinforcement (mm), $u_{e}=$ mean elastic bond stress $(\mathrm{MPa})\left(=0.9 \vee f_{c}\right), f_{c}=$ concrete compressive strength (MPa), and $S F_{\text {slip }}=$ bond-slip scale factor. By multiplying the strains of steel and concrete by $S F_{\text {slip }}$, original concrete and steel stress-strain models are transformed to concrete and steel stress-slip (displacement) models, which are employed in the zero-length fiber section element [26]. The bar-slip at the end of beams was modeled in the same manner as used in the columns.

Experimental studies suggest that bond deterioration and failure for continuous beam reinforcement anchored within the joint result in rotation at the end of beams [23,28]. Leon [29], however, states that the large amount of slip measured in laboratory tests can be largely associated with the lack of horizontal restraint, i.e., the ends of beams are restrained only vertically. In a continuous frame, such slip would not likely occur unless all the joints at a particular story experienced significant bond deterioration simultaneously. Thus, indeterminate frames could be expected to result in significantly reduced slip. Similarly, Hoffman et al. [30] concluded that for indeterminate frames, bar slip at the beam-joint interface is typically small and difficult to detect visually during testing. Hoffman et al. [30] accounted for the impact of bar slip and anchorage failure by using a reduced beam moment strength equal to the nominal yield strength multiplied by the ratio of the provided to required embedment length for the beam longitudinal reinforcement. This assumption was used in Celik and Ellingwood [20], who developed fragility curves for non-ductile frames. Thus, for modeling RC frames (Section 5.1), 
rotation at the beam-joint interface due to slip of beam reinforcement within the joint is not explicitly modeled for joints with sufficient anchorage length or for joints with short embedment lengths although the additional rotation due to the bar-slip of the beam reinforcement was modeled in the model validation.

\subsection{Model application}

The proposed joint response model, with parameters defined as recommended in Table 2, was used in the subassemblage model shown in Fig. 1 to simulate the response of test specimens not used in developing the joint response model. Fig. 4 shows the comparison of experimental and simulated results for four specimens; two specimens are interior joints exhibiting joint shear failure with and without beam yielding; one specimen is an exterior joint exhibiting joint shear failure without beam yielding; and one specimen is an exterior joint that exhibit joint shear failure when loaded in one direction and anchorage failure when loaded in the other direction. For each category of beam-column joint (interior, exterior, and exterior with anchorage failure), strength, energy dissipation, and the pinched nature of the response history are well simulated by the model, though the model provides a simplified representation of the cyclic response history. Moreover, Fig. 5 shows an example for the worst prediction. The strength is poorly simulated, but the model simulates well the pinched nature of the response history while providing a simplified representation of the cyclic response history.

Fig. 4. Experimental and model responses: for interior joints (a) PEER14 [31] and (b) J-OH [32], for exterior joint (c) Unit 6 [33], and for exterior joint with anchorage failure (d) Unit 1 [33]. 
Fig. 5. Experimental and model responses for the worst prediction (T1 [34]).

\section{Column response model}

For columns, flexural yielding and premature flexural failure associated with poor transverse reinforcement details can be simulated using basic fiber-type beam-column elements. However, these elements cannot accurately capture a rapid loss of lateral strength and axial load carrying capacity of columns resulting from shear failure [26,27,35], and thus models must be developed to simulate this non-ductile response of columns.

\subsection{Column flexure and shear response model}

Fig. 6(a) shows the OpenSees element configuration used for simulation of column response. Flexural response was simulated using fiber-type displacement-based beam-column elements located at the ends of the column and an elastic beam-column element away from the ends of the column where inelastic action is not expected; bar-slip response at the end of column was modeled introducing fiber-type zero-length section element; and details of the model are as described in Section 3.1. Shear response was simulated using a zero-length shear spring located at one end of the column.

Fig. 6. Modeling shear-dominated column: (a) finite element model and (b) shear, flexure, and total response envelopes.

A new shear load versus deformation model was developed using the existing OpenSees limit-state material model and shear limit curve developed by Elwood [35]. As shown in Fig. 
6(b), the shear limit curve is activated and shear failure is initiated once the column shear demand exceeds the column shear capacity. These models require definition of shear strength $\left(V_{n}\right)$, unloading shear stiffness $\left(K_{d e g}^{t}\right)$, and residual shear strength $\left(V_{\text {res }}\right)$. Here, to improve the accuracy of shear strength prediction, the shear strength model original employed by Elwood [35] was replaced with the ASCE 41-06 shear strength model [22,27]:

$$
V_{n}=\lambda k\left(\frac{0.5 \sqrt{f_{c}}}{M /(V d)} \sqrt{1+\frac{P}{0.5 \sqrt{f_{c} A_{g}}}}\right) 0.8 A_{g}+k \frac{A_{v} f_{y v} d}{s}
$$

where $k=$ strength degradation coefficient that depends on displacement ductility demand $\left(\mu_{\Delta}\right)(k$ $=1.0$ for $\mu_{\Delta} \leq 2, k=0.7$ for $\mu_{\Delta} \geq 6$, and linear interpolation is used for $2<\mu_{\Delta}<6$ ); $\mu_{\Delta}$ is defined as the ratio of the ultimate displacement to yield displacement. The yield displacement can be determined using the secant stiffness method while the ultimate displacement is defined as the displacement at 20\% loss of maximum shear force [27]. The current study adopts $k=1.0$ because the proposed model is a strength-based model; $\lambda=0.75$ and 1.0 for light and normal weight aggregate concrete, respectively; $P=$ axial compressive load for previous converged solution state; $M / V d=$ largest ratio of moment to shear times effective depth $(2 \leq M / V d \leq 4) ; d=$ effective depth; $A_{g}=$ gross cross-sectional area; $A_{v}=$ area of transverse reinforcement; $f_{y v}=$ yield stress of transverse reinforcement; and $s=$ spacing of transverse reinforcement.

Elwood [35] recommends that the unloading stiffness of the shear spring $\left(K_{d e g}\right)$ be defined by the unloading stiffness of the total column shear load versus drift response $\left(K_{d e g}^{t}\right)$ and the portion of the unloading flexural response that can be attributed to flexural response $\left(K_{\text {unload }}\right)$ :

$$
\frac{1}{K_{\mathrm{deg}}^{t}}=\frac{1}{K_{\text {uload }}}+\frac{1}{K_{\mathrm{deg}}}
$$


For the new model, the approach employed by Elwood [35] for defining the unloading stiffness of the column $\left(K_{d e g}^{t}\right)$ was replaced by the shear-friction based model proposed by Baradaran Shoraka [8]:

$$
K_{\mathrm{deg}}^{t}=-4.5 P\left(4.6 \frac{A_{v} f_{y v} d_{c}}{P S}+1\right)^{2} L
$$

where $d_{c}=$ depth of the column core from the centerline to centerline of transverse reinforcement and $L=$ column length. Unloading stiffness attributed to flexural response $\left(K_{\text {unload }}\right)$ was assumed equal to the initial flexural stiffness per Elwood [35]. Residual shear strength $\left(V_{\text {res }}\right)$ was assumed equal to $20 \%$ of the initial shear strength $\left(V_{n}\right)$ to alleviate the convergence issue such as numerical instability in dynamic analyses.

\subsection{Validation of proposed column shear model}

The proposed column shear failure response model is validated by comparing analytical and experimental results for a dataset comprising 30 columns; columns exhibited flexure-shear and shear failure with $M / V d$ ranging from two to four to satisfy the condition of Eq. (8). Few experimental data exist characterizing the response of columns subjected to varying axial load and exhibiting shear failure; thus, all columns in the dataset were tested under constant axial load. Table 3 identifies test specimens included in the dataset and summarizes the range of design parameters for the dataset. Most data were obtained from the database assembled by Ghannoum and Sivaramakrishnan [51]. Fig. 7 shows observed and simulated response histories for four specimens; two specimens exhibiting flexure-shear failure at the high $\left(\mu_{\Delta}>2\right)$ and low $\left(\mu_{\Delta} \leq 2\right)$ flexural ductility demands and two specimens exhibiting shear failure prior to flexural yielding. These data show that the model can provide acceptably accurate simulation of shear capacity, drift capacity, deterioration in shear strength resulting from increasing drift demand and cyclic 
response, and energy dissipation. Moreover, Fig. 8 shows an illustration for the worst prediction of the proposed model. The model underestimated the column shear capacity and associated drift demand; however, it captured well the pinched hysteretic response.

As shown in Fig. 8, the proposed strength-based model is a limitation for the estimation of deformation at shear failure. In this regard, it is not as accurate as the model of LeBorgne and Ghannoum (rotation-based limit state model) [26]. However, the proposed model is more computationally efficient and numerically robust than the LeBorgne and Ghannoum model and yields acceptable estimate of responses for the dataset of 30 specimens overall.

Cyclic response parameters for use with the OpenSees limit-state material were determined to provide a least-squares best-fit to the experimental load-drift response. For each column test, the pinching factor for deformation during unload $\left(p_{x}\right)$, pinching factor for force during unloading $\left(p_{y}\right)$, and parameter for the degraded unloading stiffness based on ductility $(\beta)$ were computed to provide a best-fit to the data for that particular test. The factor $p_{x}$ has a mean value of 0.40 and COV of 0.25 while the factor $p_{y}$ has a mean value 0.30 and COV of 0.40 . The factor $\beta$ was not used in the simulations. Thus, the average values $\left(p_{x}=0.40, p_{y}=0.35, \beta=0.0\right)$ are recommended for use in predictive analyses and were used to predict frame response for generation of fragility function.

Table 3 Summary of column experimental dataset $\uparrow$.

Fig. 7. Experimental and model responses: for flexure-shear failure (a) Specimen 1 [27] and (b) U2 [40], and for shear failure (c) Specimen 4 [46] and (d) CR96L-S0 [50]. 
Fig. 8. Experimental and model responses for the worst prediction (2CLH18 [38]).

\section{Fragility analysis}

To facilitate assessment of the seismic vulnerability of non-ductile RC frames, fragility functions defining the probability of meeting or exceeding a specific limit state given an earthquake intensity level were developed using numerical simulation and the component models described above. Using the cloud method, fragility functions were developed for the given reference frame as follows: 1) choose component response mechanisms to be considered in the analysis, 2) use Latin hypercube sampling (LHS) [52] to generate $N$ statistical samples of the frame with each sample representing a random combination of material (concrete and steel strength) and system (damping ratio) parameters, 3) select a suite of $N$ ground motions applicable to the region of interest, which account for different characteristics such as far-field versus near-fault, magnitude, distance, and soil site, 4) perform nonlinear dynamic analyses for $N$ randomly assigned frameground motion pairs (from Step 2 and Step 3), 5) for each analysis, record engineering demand parameters (EDPs) of interest (here, maximum story and roof drift) as well as ground motion intensity measures (IMs) of interest (spectral acceleration at fundamental period, $S_{a-T I}$ ), and 6) develop a probabilistic seismic demand model (PSDM) and fragility curves for four limit states.

\subsection{Description and analytical model of selected $R C$ frame}

The four-story, three-bay non-ductile RC frame designed by Liel [7], as shown in Fig. 9, was selected as a case study to implement the proposed procedure. Liel [7] designed this frame in accordance with the minimum requirements of the 1967 Uniform Building Code and for the highest seismic zone in California [9]. Fig. 9 provides beam, column and joint design data, and. a 
slab thickness of $200 \mathrm{~mm}$ was assumed; beams and slabs were as T-shaped beams using modeled and the effective width of the slab was calculated from the provisions of ACI 318-11 [16]. The floor dead load and mass were determined based on the load combination 1.05DD $+0.25 \mathrm{DL}$ (dead load, DD $=8.4 \mathrm{kPa}$ and live load, $\mathrm{DL}=2.4 \mathrm{kPa}$ ) per Ellingwood et al. [53]. As designed, the frame could be expected to exhibit one or more of the following response mechanisms under earthquake loading: (1) joint shear failure as joint shear demand computed per ACI 352R-02 [21] exceeds joint shear capacity for the joints, (2) anchorage failure for beam bottom longitudinal reinforcement anchored in the joints with $150 \mathrm{~mm}$ (6 in) anchorage lengths per the minimum requirement of ACI 318-63 [54], (3) column shear failure as shear demands associated with development of column flexural strength exceed capacity computed assuming concrete does not contribute to shear strength per ACI 318-11 Section 21.5.4.2 [16] (concrete contribution of shear strength is taken as zero for columns subjected to (a) more than $50 \%$ of shear demand and (b) axial load less than $0.05 f_{\mathrm{c}} A_{\mathrm{g}}$ ), and (4) beam yielding in flexure as shear demands in beams do not exceed capacity assuming zero concrete contribution to strength. However, to investigate the impact of component response mechanisms on building performance and vulnerability, five models of the frame were created using OpenSees and the component models discussed above. These five models, as shown in Fig. 10 and Table 4, included simulation of beam and column flexural response as described in the beam-column joint subassemblage modeling effort and included simulation of (1) beam-column joints using essentially rigid frame elements within the joint region (Model 1), (2) joint shear failure (Model 2), (3) joint failure as controlled by either shear strength or beam rebar anchorage strength (Model 3), (4) column shear failure (Model 4), and (5) joint failure as controlled by shear as well as column shear failure (Model 5). 


\section{Fig. 9. Design information of 4-story non-ductile space frame [7].}

Fig. 10. Analytical frame models: (a) rigid joint response (Model 1), (b) joint shear response without anchorage failure (Model 2), (c) joint shear response with anchorage failure (Model 3), (d) column shear response (Model 4), and (e) joint and column shear response (Model 5).

Table 4 Component modeling for frame models.

For Model 4 and Model 5, the potential of column shear failure is identified through the comparison of column shear demand and capacity. As mentioned before, according to ACI 31811 [16], the concrete contribution of shear capacity can be ignored if the two conditions such as less than $0.05 f_{c} A_{g}$ and more than $50 \%$ of shear demand are satisfied. For the subject frame, the axial load ratio $\left(P / f_{c} A_{g}\right)$ on the exterior and interior columns ranges from 0.033 to 0.137 and from 0.074 to 0.292 , respectively. Therefore, the former was not satisfied for most columns, and thus the concrete contribution might be included. However, if columns would be expected to experience moderate to severe deformation demands, no concrete contribution might be acceptable. The above two conditions drew different conclusions for the addition of concrete contribution to shear strength. Thus, the current study used both the ACI318-11 equation (no concrete contribution to shear strength) and ASCE 41-06 equation (Eq. (8)) (concrete does contribute to shear strength within the column hinge region) for the calculation of shear capacity. Although columns have the potential for exhibiting shear failure when column shear strength is defined per ACI 318-11 (no concrete contribution), when column shear strength is defined per Eq. (8) (concrete contribution) column shear demands do not exceed shear capacity. Thus, to 
investigate the impact of column shear failure on frame fragilities using Model 4 and Model 5, columns were redesigned to be shear-critical. Specifically, column transverse reinforcement spacing was increased by $340 \mathrm{~mm}$ for the first-story exterior and second-story interior columns and by $500 \mathrm{~mm}$ for the first-story interior columns.

\subsection{Probabilistic analytical frame models and ground motion suite}

Aleatoric uncertainty (inherently random in nature) in concrete compressive strength $\left(f_{c}\right)$, steel yield strength $\left(f_{y}\right)$, and damping ratio $(\zeta)$ is incorporated in the analyses using the LHS technique. This technique provides a more efficient sampling scheme to cover the probability space of the random variables when compared with pure random sampling using naïve Monte Carlo simulation [4]. Table 5 shows the modeling parameters and their associated probability distributions provided by Healy et al. [55] and Liel [7]. The material parameters $f_{c}$ and $f_{y}$, sampled using the LHS technique, were used to compute joint shear strength, anchorage (bond) strength, and column shear strength for the frame.

Table 5 Modeling uncertainties.

Assembling a suite of ground motions that represents the seismic hazard is crucial to developing fragility curves applicable to RC frames spread over a wide geographic area. The suite of ground motions must contain a wide range of IMs expected in the interest area based on seismic hazard analysis. To accomplish this purpose, this study selects a suite of ground motions

developed by Baker et al. [56] that can be utilized to analyze a variety of structures potentially located in active seismic regions such as California. 


\subsection{Simulated response}

The influence of component response, as characterized by the five models described previously, on overall behavior of the frame was investigated by comparing the simulation results, for individual ground motion records, generated using the different frame models. Fig. 11 shows the comparison of response histories for a first-story interior column for three of the models described above: a) joint shear failure is simulated (Model 2), b) columns are redesigned and column shear failure is simulated (Model 4), and c) joint shear and column shear failure are simulated (Model 5). The data in Fig. 11 suggest that, for the design and redesign considered, beam-column joint failure occurred prior to column shear failure and limited column shear demand such that column shear failure was avoided. This is supported by the larger column shear shown in Fig. 11b and the essentially identical response histories shown in Figs. 11a and 11c. Comparison of the data in Figs. 11a and $11 \mathrm{~b}$ also shows a $120 \%$ increase in maximum story drift when joint shear failure occurs instead of column shear failure. Fig. 12 shows the comparison of response histories for the following models: a) joint shear failure simulated (Model 2) and b) joint shear and anchorage failure simulated (Model 3). These data show that simulation of anchorage failure for beam reinforcement terminating in the joint results is a slight reduction in strength and thus column shear force demand (approximately 8\%) and an increase in story drift $(20 \%)$.

Fig. 11. Comparison of column shear-story drift responses for first-story interior column: (a) joint shear response (Model 2), (b) column shear response (Model 4), and (c) joint and column shear response (Model 5). 
Fig. 12. Comparison of column shear-story drift response for first story exterior column: (a) joint shear response (Model 2) and (b) joint shear/anchorage response (Model 3).

To examine the distribution of damage for different response mechanisms, Fig. 13 shows the comparison of maximum story drift distribution along each story level for different frame models. Column flexure (Fig. 13a) and shear (Fig. 13d) response model have relatively higher maximum story drift at the first and second stories due to the accelerated damage accumulation at these story columns. The column shear response model (Model 4) has lower first-story drift and higher second-story drift compared to the column flexure response model (Model 1). This is due to the fact that the first and second story columns exhibited shear failure and experienced more distributed damage over these columns. In contrast, for joint response models (Model 2 and Model 3) shown in Figs. 13b and 13c, structural damage is distributed over all frame stories: smaller first story drift demand and larger third and fourth story drift demand than the column flexure and column shear response models (Model 1 and Model 4). Furthermore, as shown in Figs. 13a and 13c, the combined joint and column shear response model (Model 5) provides the same results as the joint shear response model (Model 2) because joint shear response controlled overall system response.

Fig. 13. Maximum story drift distribution: (a) rigid joint response (Model 1), (b) joint shear response (Model 2), (c) joint shear/anchorage response (Model 3), (d) column shear response (Model 4), and (e) joint and column shear response (Model 5). 


\subsection{Probabilistic seismic demand models}

Nonlinear dynamic analyses for 160 randomly selected pairs of frame models and ground motions were performed to determine EDPs and associated IMs. These quantities are required to generate the PSDM, which relates the median EDP on the structure to the IM, suggested by Cornell et al. [57]:

$$
S_{D}=a \cdot I M^{b}
$$

where $S_{D}$ is the median value of the demand as a function of an IM, parameters $a$ and $b$ can be computed by a linear regression analysis of $\ln \left(S_{D}\right)$ on $\ln (I M)$ obtained from simulations. In this study, maximum story drift ratio $\left(\theta_{\max }\right)$ and spectral acceleration at the fundamental period $\left(S_{a-T I}\right)$ are chosen as $S_{D}$ and IM, respectively. Here, the average value of $S_{a-T l}$ for different frame models was used to compare the demands and fragility curves for these models because the fundamental periods do not vary significantly for the models ( $9 \%$ of maximum difference); a mean value of $1.07 \mathrm{sec}$ and COV of 0.02 for Model 1 and Model 4 and a mean of $1.17 \mathrm{sec}$ and COV of 0.02 for Model 2, Model 3, and Model 5. Additionally, the mean value of $S_{a-T l}$ ranges from $0.305 \mathrm{~g}$ to $0.330 \mathrm{~g}$ for the different frame models, and the average $S_{a-T l}$ is $0.315 \mathrm{~g}$ for all frame models.

Comparison of the PSDMs for the five frame models, as shown in Fig. 14, indicates that the component response model does not significantly affect the seismic demand considered in this study $\left(\theta_{\max }\right)$. For example, given a $S_{a-T l}$ of $1.1 \mathrm{~g}$, the maximum story drift ranges from $4.3 \%$ to $5.2 \%$ for the frame models. Column flexure and column shear response models (Model 1 and Model 4), shown in Figs. 14a and 14d, result in slightly larger seismic demands. Detailed evaluation of analysis results suggests that this is due to development of a soft-story collapse mechanism and thus concentration of story drift demands. In contrast, when the potential for joint but not column shear failure is included in the model (Model 2), structural damage is 
distributed over all frame stories (Fig. 13 and Fig. 15), resulting in higher maximum roof drift demand, as shown in Fig. 16. This observation is consistent with the work of Celik and Ellingwood [20]. Comparison of data in Figs. $14 \mathrm{~b}$ and $14 \mathrm{c}$ indicates that the development of a joint anchorage failure mechanism (Model 3) could be expected to result in slightly larger story drift demands than development of a pure joint shear response model (Model 2). Finally, similar demands are predicted if only joint shear failure (Model 2) is simulated (Fig. 14b) or if joint and column shear failure (Model 5) are simulated (Fig. 14e). This supports the anecdotal observation of frame response discussed above (Section 5.3) that joint failure controls over column shear failure. Thus, the concurrent joint and column shear response model (Model 5) in Fig. 14e is approximately the same as that for the joint shear response model (Model 2) in Fig. 14b.

Fig. 14. PSDMs with different analytical frame models: (a) rigid joint response (Model 1), (b) joint shear response (Model 2), (c) joint shear response and anchorage failure (Model 3), (d) column shear response (Model 4), and (e) joint and column shear response (Model 5).

Fig. 15. PSDMs for maximum story drift demand along each story level: (a) rigid joint response (Model 1), (b) joint shear response (Model 2), and (c) column shear response (Model 4).

Fig. 16. PSDMs for maximum roof drift demand: (a) rigid joint response (Model 1) and (b) joint shear response (Model 2).

Fig. 15 shows the damage distribution at each story level for Model 1, Model 2, and Model 4 through their respective PSDM. Analyzing the regression coefficients demonstrated that 
Model 2 (joint shear response) exhibited distributed damage over the first to third story level (larger values of regression coefficients $a$ and $b$ in Eq. (11)) while Model 1 and Model 4 (without joint flexibility) experienced more concentrated damage on the first and second stories.

\subsection{Fragility curves}

Outputs obtained from the linear regression analysis in a log-transformed space (PSDM) and empirically-based limit-state models may be used to develop closed-form expressions for fragility functions, assuming limit-state models also follow a lognormal distribution:

$$
P[D>C \mid I M]=\Phi\left[\frac{\ln \left(S_{D} / S_{C}\right)}{\sqrt{\beta_{D \mid M}^{2}+\beta_{C}^{2}+\beta_{M}^{2}}}\right]
$$

where $D$ and $C$ are seismic demand and structural capacity, respectively; $S_{D}$ and $\beta_{D \mid I M}$ are the median value and dispersion of the demand as a function of $S_{a-T 1}$, respectively; $S_{C}$ and $\beta_{C}$ are the median value and dispersion of the structural limit state, respectively; $\beta_{M}$ is the modeling uncertainty (assumed to be 0.2 per Celik and Ellingwood [4]); and $\Phi[\cdot]$ is the cumulative normal distribution function. For this study, limit-state models define the demand at the onset of various structural damage states. Median values $\left(S_{C}\right)$ of four damage states are presented in Table 6. On the basis of the damage description for four limit states presented in HAZUS-MH [58], the median value for each limit state was assumed using previous studies $[4,58,59]$. The dispersion $\left(\beta_{C}\right)$ of all limit states is assumed to be 0.3 per Wen et al. [60].

Table 6 Capacity limit state model for maximum story drift (\%). 
Fig. 17 shows the comparison of the resulting fragility curves at the extensive and complete damage states for four of the five frame models. Fragilities for the model in which joint and column shear failure (Model 5) are simulated are not presented as results are essentially identical to those of the model in which only joint shear failure is simulated (Model 2). Differences in the fragility curves are most easily evaluated by comparing the median intensity measure (defined as an intensity measure at a 50\% probability of reaching a specific limit state). Fig. 18 shows the comparison of these median intensity measures of $S_{a-T l}$ at the four limit states for the four frame models. For the models in which column or joint shear failure is simulated (Models 2-5), the impact of the component response model on median intensity at onset of a limit state is less than 10\% except for the complete limit state (15\% difference between Model 2 and Model 4). The most vulnerable structure is that in which columns exhibit shear failure (Model 4) while the least vulnerable structure is that in which beams and columns exhibit only flexural yielding and joints are assumed rigid (Model 1). Moreover, although Model 1 has higher seismic demands (maximum story drift) than Model 1, as shown in Figs. 13-15, Model 1 is the least vulnerable. This is due to the definition of the limit state models presented in Table 6, namely that flexure-controlled members have more sufficient seismic resistance than shearcontrolled members.

Accounting for non-ductile response mechanisms such as joint failure or column failure (Models 2-5) increases frame vulnerability over that predicted for the pure flexural response model (Model 1). Thus, these mechanisms should be included in the frame models to provide reliable simulation of seismic risk. Additionally, the resulting fragilities for the non-ductile response models are insensitive to the response mechanisms at lower (slight and moderate) damage levels as well as not particularly sensitive to the mechanism at higher (extensive and 
complete) damage levels (less than 10\% difference except for one case). Thus, it is reasonable to choose to use only the fragility of one non-ductile response model, likely the most conservative, for the assessment of building inventories. However, these results are not definitive, and thus all response mechanisms should be considered to develop fragilities for the reliable vulnerability assessment of different buildings.

Fig. 17. Comparison of fragility curves with different frame models: (a) extensive and (b) complete damage state.

Fig. 18. Median intensity measures of fragility curves with different frame models.

\subsection{Impact of aleatoric uncertainty on frame vulnerability}

To examine the effect of aleatoric uncertainties such as $f_{c}, f_{y}$, and $\zeta$ on the seismic vulnerability of the RC frame, the joint shear response model (Model 2) and column shear response model (Model 4) were employed with the mean value of three parameters $\left(f_{c}=27.6 \mathrm{MPa}, f_{y}=462 \mathrm{MPa}\right.$, and $\zeta=0.05)$ and fragility curves were developed using the approach presented above. Figs. 19a and 19b show the comparison of fragility curves for Model 2 and Model 4, respectively, for all limit states with and without aleatoric uncertainties. For both models, accounting for aleatoric uncertainties has little impact on the fragility curves; consideration of aleatoric uncertainty results in a variation in the median values of $S_{a-T l}$ less than $2 \%$. Thus, the data indicate that it is not necessary to consider aleatoric uncertainty in assessment of earthquake damage and/or loss for RC frames. This observation is consistent with the results of other studies [20,61]. 
Fig. 19. Comparison of fragility curves with and without aleatoric uncertainty: (a) joint shear response model (Model 2) and (b) column shear response model (Model 4).

\section{Summary and Conclusions}

This paper aims at using numerical simulation to develop fragility curves for non-ductile RC frames. Numerical models are developed that provide appropriate and numerically efficient and robust simulation of the primary response modes of non-conforming $\mathrm{RC}$ joints and columns. These models employ existing OpenSees materials and element formulations and are developed using large experimental databases. The joint response model employs a new joint shear strength model that was calibrated using stepwise multiple regression analysis and an extensive experimental dataset; new cyclic response parameters were determined to provide a least-squares best-fit to the experimental data. This model simulates joint shear failure prior to and following flexural yielding of framing members (beams or columns) as well as premature anchorage failure. A column shear response model is developed by combining an existing column shear strength model with an existing material model; the model can simulate flexure-shear or shear failure. Cyclic response parameters are determined to provide a least-squares best-fit method to experimental data. Although the response models provide poor predictions for a few specimens, the simulated responses for most specimens are good. As a result, these response models can provide reliable earthquake risk assessment by reducing modeling uncertainties.

To investigate the impact of component response models on frame vulnerability, a nonductile RC frame is selected as a case study. Numerical models of this frame are developed, which account for simulation of one or more response characteristics: (1) rigid joint, (2) inelastic joint shear response, (3) nonlinear joint shear response and anchorage failure, (4) column shear failure. For these frame models, nonlinear dynamic analyses are performed using a suite of 
ground motions representative of the seismic hazard of California. The fragility results reveals that (1) for the shear response models, median intensity measures and median story drifts were not significantly affected by the component response models (results for different models vary by less than 15\%), (2) the most vulnerable frame is that in which joint shear failure is assumed not to occur and only column shear failure is simulated (Model 4) whereas the least vulnerable frame has the rigid joint model (Model 1), (3) the models without joint flexibility (Model 1 and Model 4) caused larger seismic demands, likely due to the development of a soft-story collapse mechanism while for the models with joint flexibility (Models 2, 3, and 5), seismic demands were distributed over all stories, (4) simulation of joint anchorage failure (Model 3) resulted in a slight increase in seismic demand compared with the model in which only joint shear failure (Model 2) was simulated, and (5) the combined joint and column shear response model (Model 5) results in approximately the same seismic demands as the joint shear response model (Model 2). However, this observation is valid only for RC buildings, especially where the softening of one component alleviates demands on other critical components. Thus, simulation of both joint and column shear failure is recommended for fragility assessment of non-ductile RC frames, because, in general, either response mechanism may control frame response. Finally, accounting for aleatoric uncertainties has little impact on frame fragility curves, and thus a deterministic frame model is sufficient for earthquake damage assessment for older RC frames in California.

\section{Acknowledgments}

This research was supported by the National Science Foundation under NSF Grant \# 1000700. However, the views expressed are solely those of the authors and may not represent the position of the NSF. 


\section{Nomenclature}

$A_{j}$ : joint area $\left(\mathrm{mm}^{2}\right)$.

$A_{g}$ : gross sectional area of column $\left(\mathrm{mm}^{2}\right)$.

$A_{v}$ : area of transverse reinforcement $\left(\mathrm{mm}^{2}\right)$.

$B I$ : beam reinforcement index.

$C$ : structural capacity.

COV: coefficient of variation.

$D$ : seismic demand.

DD: dead load.

DL: live load.

$J P$ : parameter for describing in-plane geometry.

$K_{\text {deg: }}$ : unloading stiffness of the shear spring $(\mathrm{N} / \mathrm{mm})$.

$K_{\text {deg: }}^{t}$ unloading shear stiffness $(\mathrm{N} / \mathrm{mm})$.

$K_{\text {unload: }}$ Unloading stiffness attributed to flexural response $(\mathrm{N} / \mathrm{mm})$.

$L$ : column length (mm).

$L_{b}$ : total length of the left and right beams $(\mathrm{mm})$.

$L_{c}$ : total length of the top and bottom columns ( $\left.\mathrm{mm}\right)$.

$L_{p}$ : plastic hinge length of members $(\mathrm{mm})$.

$M / V d$ : largest ratio of moment to shear times effective depth.

$M_{j}$ : joint rotational moment $(\mathrm{N}-\mathrm{mm})$.

$P$ : column axial load $(\mathrm{N})$.

$S_{a-T 1}$ : spectral acceleration at the fundamental period (g).

$S_{C}$ : median value of the structural limit state.

$S F_{\text {slip }}$ : bond-slip scale factor.

$S_{D}$ : median value of the demand as a function of an intensity measure.

$T B$ : joint confinement factor

$T_{s}$ : maximum tension force developed in the poorly anchored beam bottom reinforcement $(\mathrm{N})$.

$V_{n}$ : column shear strength $(\mathrm{N})$.

$V_{\text {res }}$ : residual shear strength $(\mathrm{N})$.

$f_{c}$ : concrete compressive strength $(\mathrm{MPa})$.

$b_{j}$ : effective width of the joint panel calculated from ACI 352R-02 (mm).

$c$ : minimum of bottom and side concrete cover $(\mathrm{mm})$.

$d$ : column effective depth (mm).

$d_{c}$ : depth of the column core from centerline to the centerline of transverse reinforcement $(\mathrm{mm})$. 
$d_{b}$ : effective depth of the beam (mm).

$f_{y}$ : yield stress of longitudinal reinforcement $(\mathrm{MPa})$.

$f_{y v}$ : yield stress of transverse reinforcement $(\mathrm{MPa})$.

$h_{c}$ : column depth (mm).

$j$ : internal moment arm factor.

$k$ : strength degradation coefficient

$k_{\text {deg: }}$ : post-peak stiffness in joint shear stress-strain curve (MPa/rad).

$l_{b}$ : beam length measured from the face of column to the end of beam ( $\left.\mathrm{mm}\right)$.

$l_{s p}:$ embedment length within a joint $(\mathrm{mm})$.

$n_{b}$ : number of beam bottom longitudinal rebars.

$p_{x}$ : pinching factor for deformation during unload.

$p_{y}$ : pinching factor for force during unloading.

$s$ : spacing of transverse reinforcement $(\mathrm{mm})$.

slip $_{y}$ : bar slip at yield (mm).

$u_{e}$ : mean elastic bond stress (MPa).

$\Phi[\cdot]$ : cumulative normal distribution function.

$\Psi_{s}$ : reinforcement factor.

$\Omega$ : transverse beam confinement factor.

$\alpha_{*}$ : parameters for us in fitting the damage rule to experimental data.

$\beta$ : parameter for the degraded unloading stiffness based on ductility.

$\beta_{C}$ : dispersion of the structural limit state.

$\beta_{D \mid I M}$ : dispersion of the demand as a function of an intensity measure.

$\beta_{M}$ : modeling uncertainty.

$\gamma_{3}$ : shear strain corresponding to maximum joint shear stress (rad).

$\gamma_{j}$ : joint shear strain (rad).

$\varepsilon_{y}$ : longitudinal reinforcement yield strain.

$\zeta$ : damping ratio.

$\eta: 2$ and 1 for the top floor joints and others.

$\theta_{j}$ : joint rotation $(\mathrm{rad})$.

$\theta_{\max }:$ maximum story drift ratio (\%).

$\mu_{\Delta}$ : displacement ductility demand.

$\tau_{\text {bond }}$ : maximum average bond stress ( $\left.\mathrm{MPa}\right)$

$\tau_{j}$ : joint shear stress $(\mathrm{MPa})$.

$\tau_{\max }$ : maximum joint shear stress (MPa). 
$\phi_{b}$ : diameter of beam bottom rebars $(\mathrm{mm})$

$\phi_{c}$ : diameter of column longitudinal rebars $(\mathrm{mm})$.

\section{References}

1. Earthquake Engineering Research Institute (EERI). Northridge earthquake January 17, 1994, preliminary reconnaissance report. Ed. J.F. Hall. Oakland, CA; 1994.

2. Comartin CD, Greene M, Tubbesing SK. The Hyogo-Ken Nanbu earthquake Great Hanshin earthquake disaster January 17, 1995, preliminary reconnaissance report. Earthquake Engineering Research Institute, Oakland, CA; 1995.

3. Sezen H, Elwood KJ, Whittaker AS, Mosalam KM, Wallace JW, Stanton JF. Structural engineering reconnaissance of the August 17, 1999 earthquake: Kocaeli (Izmit), Turkey Pacific Earthquake Engineering Research Center, University of California, Berkeley, CA, PEER Report 2000/09; 2000.

4. Celik OC, Ellingwood BR. Seismic fragilities for non-ductile reinforced concrete frames-Role of aleatoric and epistemic uncertainties. Struct Saf 2010;32(1):1-12.

5. Jeon J-S, DesRoches R, Brilakis I, Lowes LN. Modeling and fragility analysis of non-ductile reinforced concrete buildings in low-to-moderate seismic zones. In: ASCE Structures Congress, Chicago, IL; 2012, p. 2199-210.

6. ACI Committee 318. Building code requirements for reinforced concrete (ACI 318-89) and commentary (ACI 318R-89). Detroit, MI, American Concrete Institute; 1989.

7. Liel AB. Assessing the collapse risk of California's existing reinforced concrete frame structures: Metrics for seismic safety decisions. Ph.D. thesis, Department of Civil and Environmental Engineering, Stanford University, CA; 2008.

8. Baradaran Shoraka M. Collapse assessment of concrete buildings: An application to non-ductile reinforced concrete moment frames. Ph.D. thesis, Department of Civil Engineering, The University of British Columbia, Canada; 2013.

9. International Conference of Building Officials. Uniform Building Code. Whittier, CA; 1967.

10. Baker JW, Cornell CA. Vector-valued ground motion intensity measures for probabilistic seismic demand analysis. Pacific Earthquake Engineering Research Center, University of California, Berkeley, CA, PEER Report 2006/08; 2006.

11. McKenna F, Scott MH, Fenves GL. Nonlinear finite-element analysis software architecture using object composition. ASCE J Comput Civ Eng 2010;24(1):95-107.

12. Jeon J-S. Aftershock vulnerability assessment of damaged reinforced concrete buildings in California. Ph.D. thesis, School of Civil and Environmental Engineering, Georgia Institute of Technology, GA; 2013. 
13. Jeon J-S, Lowes LN, DesRoches R. Numerical models for beam-column joints in reinforced concrete building frames. ACI Special Publication 2014; 297:3.1-3.26.

14. Berry MP, Lehman DE, Lowes LN. Lumped-plasticity model for performance simulation of bridge columns. ACI Struct J 2008; 105(3):270-79.

15. Mander JB, Priestley MJN, Park R. Theoretical stress-strain model for confined concrete. ASCE J Struct Eng 1988;114(8);1804-26.

16. ACI Committee 318. Building code requirements for reinforced concrete (ACI 318-11) and commentary. Farmington Hills, MI, American Concrete Institute; 2011.

17. Anderson M, Lehman D, Stanton J. A cyclic shear stress-strain model for joints without transverse reinforcement. Eng Struct 2008;30(4):941-54.

18. Kim J, LaFave JM. Joint shear behavior of reinforced concrete beam column connections subjected to seismic lateral loading. Department of Civil and Environmental Engineering, University of Illinois at Urbana-Champaign, IL, Report No. NSEL-020; 2009.

19. Alath S, Kunnath SK. Model Alath S, Kunnath SK. Modeling inelastic shear deformations in RC beam-column joints. In: Engineering Mechanics, Proceedings of 10th Conference, University of Colorado at Boulder, CO, ASCE; 1995, p. 822-5.

20. Celik OC, Ellingwood BR. Modeling beam-column joints in fragility assessment of gravity load designed reinforced concrete frames. J Earthquake Eng 2008;12(3):357-81.

21. Joint ACI-ASCE Committee 352. Recommendations for design of beam-column connections in monolithic reinforced concrete structures (ACI 352R-02). Farmington Hills, MI, American Concrete Institute; 2002.

22. Elwood KJ, Matamoros AB, Wallace JW, Lehman D, Heintz JA, Mitchell AD, Moore MA, Valley MT, Lowes LN, Comartin CD, Moehle JP. Update to ASCE/SEI 41 concrete provisions. Earthquake Spectra 2007;23(3):493-523.

23. Hassan WM. Analytical and experimental assessment of seismic vulnerability of beam-column joints without transverse reinforcement in concrete buildings. Ph.D. thesis, Department of Civil and Environmental Engineering, University of California, Berkeley, CA; 2011.

24. Berry MP, Eberhard MO. Performance modeling strategies for modern reinforced concrete bridge columns. Pacific Earthquake Engineering Research Center, University of California, Berkeley, CA, PEER Report 2007/07; 2008.

25. Zhao J, Sritharan S. Modeling of strain penetration effects in fiber-based analysis of reinforced concrete structures. ACI Structural Journal 2007;104(2):133-141. 
26. LeBorgne M, Ghannoum W. Analytical element for simulating lateral-strength degradation in reinforced concrete columns and other frame members. ASCE J Struct Eng 2013; 10.1061/(ASCE)ST.1943-541X.0000925.

27. Sezen H. Seismic behavior and modeling of reinforced concrete building columns. Ph.D. thesis, Department of Civil and Environmental Engineering, University of California, Berkeley, CA; 2002.

28. Kaku T, Asakusa H. Bond and anchorage of bars in reinforced concrete beam-column joints. Design of Beam-Column Joints for Seismic Resistance (ACI SP-123), Detroit, MI, American Concrete Institute; 1991, p. 401-23.

29. Leon RT. Interior joints with variable anchorage lengths. ASCE J Struct Eng 1989;115(9):2261-75.

30. Hoffman GW, Kunnath SK, Mander JB, Reinhorn AM. Gravity-load designed reinforced concrete buildings: Seismic evaluation strategies for improved seismic resistance. National Center of Earthquake Engineering Research, State University of New York at Buffalo, NY, Technical Report NCEER-92-0016; 1992.

31. Walker SG. Seismic performance of existing reinforced concrete beam-column joints. M.S. thesis, Department of Civil and Environmental Engineering, University of Washington, Seattle, WA; 2001.

32. Goto Y, Joh O. An experimental study on shear failure mechanism of RC interior beam-column joints. In: Eleventh World Conference Earthquake Engineering, Acapulco, Mexico; 1996, Paper No. 1194.

33. Pantelides CP, Hansen J, Nadauld J, Reaveley LD. Assessment of reinforced concrete building exterior joints with substandard details. Pacific Earthquake Engineering Center, University of California, Berkeley, CA, PEER Report 2002/18; 2002.

34. Ghobarah A, Said A. Shear strengthening of beam-column joints. Eng Struct 2002;24(7):881-8.

35. Elwood KJ. Modelling failures in existing reinforced concrete columns. Can J Civ Eng 2004;31(5):846-59.

36. Aboutaha RS, Engelhardt MD, Jirsa JO, Kreger ME. Rehabilitation of shear critical concrete columns by use of rectangular steel jackets. ACI Struct J 1999;96(1):68-78.

37. Kokusho S. Report by Building Research Institute, Tsukuba, Japan; 1964.

38. Lynn AC, Moehle JP, Mahin SA, Holmes WT. Seismic evaluation of existing reinforced concrete building columns. Earthquake Spectra 1996;12(4):715-39.

39. Pandey GR, Mutsuyoshi H. Seismic performance of reinforced concrete piers with bond-controlled reinforcements. ACI Struct J 2005;102(2):295-304.

40. Saatcioglu M, Ozcebe G. Response of reinforced concrete columns to simulated seismic loading. ACI Struct J 1989;86(1):3-12.

41. Saatcioglu M, Yalcin C. External prestressing concrete columns for improved seismic shear resistance. ASCE J Struct Eng 2003;129(8):1057-70. 
42. Takeda T, Yoshioka K. Report of the engineering research laboratory, Ohbayashi-Gumi Ltd., Japan; 1970.

43. Umehara H, Jirsa JO. Shear strength and deterioration of short reinforced concrete columns under cyclic deformations. Department of Civil Engineering, The university of Texas at Austin, TX, PMFSEL Report No. 82-3; 1982.

44. Umemura H, Endoh T. Report by Umemura laboratory, Tokyo University, Japan; 1970.

45. Wight JK, Sozen MA. Shear strength decay in reinforced concrete columns subjected to large deflection reversals. University of Illinois at Urbana-Champaign, IL, Structural Research Series No. $403 ; 1973$.

46. Woods C. Displacement demand effects in vulnerable reinforced concrete columns. M.S. thesis, Department of Civil and Environmental Engineering, University of Kansas, Lawrence, KS; 2009.

47. Yoshimura M, Nakamura T. Intermediate-story collapse of concrete buildings. In: Proceedings of 3rd U.S.-Japan Workshop on Performance-Based Earthquake Engineering Methodology for Reinforced Concrete Building Structures, Seattle, WA; 2002, p. 107-18.

48. Yoshimura M, Takaine Y, Nakamura T. Collapse of reinforced concrete columns. In: Proceedings of 5th U.S.-Japan Workshop on Performance-Based Earthquake Engineering Methodology for Reinforced Concrete Building Structures, Pacific Earthquake Engineering Research Center, Berkeley, CA; 2003, p. 239-53.

49. Yoshimura M, Yamanaka N. Ultimate limit state of RC columns. In: Proceedings of 2nd U.S.-Japan Workshop on Performance-Based Earthquake Engineering Methodology for Reinforced Concrete Building Structures, Sapporo, Hokkaido, Japan; 2000, p. 313-26.

50. Zhong P, Yamakawa T. Experimental study on elastoplastic behavior of RC columns retrofitted by steel plates or tubes. Proc Jpn Conc Inst 1997;19(2):1635-40.

51. Ghannoum W, Sivaramakrishnan B. ACI 369 rectangular column database. Network for Earthquake Engineering Simulation (NEES), Dataset, DOI:10.4231/D36688J50; 2012.

52. Mckay MD, Conover WJ, Beckman RJ. A comparison of three methods for selecting values of input variables in the analysis of output from a computer code. Technometrics 1979;21(2):239-45.

53. Ellingwood B, Galambos TV, MacGregor JG, Cornell CA. Development of a probability based load criterion for American national standard A58: Building code requirements for minimum design loads in buildings and other structures. National Bureau of Standards, U.S. Department of Commerce; 1980.

54. ACI Committee 318. Building code requirements for reinforced concrete (ACI 318-63) and commentary (ACI 318R-63). Detroit, MI, American Concrete Institute; 1963.

55. Healy JJ, Wu ST, Murga M. Structural building response review. NUREG/CR-1423, 1, US Nuclear Regulatory Commission, Washington, DC; 1980. 
56. Baker JW, Shahi SK, Jayaram N. New ground motion selection procedures and selected motions for the PEER Transportation Research Program. Pacific Earthquake Engineering Research Center, University of California, Berkeley, CA, PEER Report 2011/03; 2011.

57. Cornell AC, Jalayer F, Hamburger RO. Probabilistic basis for 2000 SAC Federal Emergency Management Agency steel moment frame guidelines. ASCE J Struct Eng 2002;128(4):526-32.

58. FEMA. HAZUS-MH MR4 technical manual, earthquake model. Federal Emergency Management Agency, Washington, DC; 2003.

59. German S, Jeon J-S, Zhu Z, Bearman C, Brilakis I, DesRoches R, Lowes L. Machine vision enhanced post-earthquake inspection. ASCE J Comput Civ Eng 2013;27(6):622-34.

60. Wen YK, Ellingwood BR, Bracci J. Vulnerability function framework for consequence-based engineering. Mid-America Earthquake Center, University of Illinois at Urbana-Champaign, IL, MAE Center Project DS-4 Report; 2004.

61. Kwon OS, Elnashai A. The effect of material and ground motion uncertainty on the seismic vulnerability of RC structure. Eng Struct 2006;28(2):289-303. 


\section{List of Tables}

Table 1 Summary of complete experimental dataset.

Table 2 Recommended modeling parameters of Pinching4 material.

Table 3 Summary of column experimental dataset ${ }^{\dagger}$.

Table 4 Component modeling for frame models.

Table 5 Modeling uncertainties.

Table 6 Capacity limit state model for maximum story drift (\%). 
Table 1 Summary of complete experimental dataset.

\begin{tabular}{|c|c|c|c|c|c|c|c|c|}
\hline $\begin{array}{l}\text { Joint } \\
\text { type }\end{array}$ & Statistics & $f_{c}(\mathrm{MPa})$ & $\begin{array}{c}\tau_{\exp } / \sqrt{f_{c}} \\
(\sqrt{\mathrm{MPa}})\end{array}$ & $\begin{array}{c}\tau_{\text {design }} / \sqrt{ } f_{c} \\
(\sqrt{\mathrm{MPa}})\end{array}$ & $\begin{array}{c}\mu \\
(\sqrt{\mathrm{MPa}})\end{array}$ & $\rho_{j}$ & $\rho_{b}$ & $\rho_{c}$ \\
\hline \multirow[t]{4}{*}{ Exterior } & Minimum & 8.3 & 0.35 & 0.25 & 1.41 & 0.000 & 0.003 & 0.005 \\
\hline & Maximum & 100.80 & 1.54 & 3.20 & 7.74 & 0.013 & 0.041 & 0.055 \\
\hline & Mean & 33.00 & 0.84 & 1.20 & 3.47 & 0.001 & 0.013 & 0.025 \\
\hline & $\mathrm{COV}$ & 0.37 & 0.29 & 0.43 & 0.37 & 1.977 & 0.482 & 0.421 \\
\hline \multirow[t]{4}{*}{ Interior } & Minimum & 11.57 & 0.47 & 0.72 & 1.00 & 0.000 & 0.006 & 0.009 \\
\hline & Maximum & 74.20 & 2.12 & 6.45 & 5.38 & 0.003 & 0.039 & 0.068 \\
\hline & Mean & 30.03 & 1.28 & 2.18 & 3.10 & 0.000 & 0.015 & 0.027 \\
\hline & $\mathrm{COV}$ & 0.37 & 0.28 & 0.54 & 0.34 & 4.024 & 0.461 & 0.478 \\
\hline
\end{tabular}

Table 2 Recommended modeling parameters of Pinching4 material.

\begin{tabular}{|c|c|c|c|c|c|c|c|c|c|c|}
\hline \multirow{2}{*}{$\begin{array}{l}\text { Joint } \\
\text { type }\end{array}$} & \multirow{2}{*}{ Failure } & \multicolumn{3}{|c|}{ Envelope } & \multicolumn{6}{|c|}{ Cyclic response parameters $\dagger$} \\
\hline & & $\tau_{\max }$ & $\gamma_{3}$ & $k_{\operatorname{deg}}(\mathrm{MPa} / \mathrm{rad})$ & rDisp & rForce & uForce & $\alpha_{\mathrm{K} 1}$ & $\alpha_{\mathrm{D} 1}$ & $\alpha_{\mathrm{F} 1}$ \\
\hline \multirow[t]{2}{*}{ Exterior } & Shear & Eq. (2) & 0.015 & 7 & \multirow{3}{*}{0.20} & \multirow{3}{*}{0.20} & \multirow{3}{*}{0.0} & \multirow{2}{*}{0.95} & \multirow{2}{*}{0.35} & \multirow{2}{*}{0.05} \\
\hline & Anchorage & Eq. (3) & 0.010 & 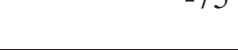 & & & & & & \\
\hline Interior & Shear & Eq. (2) & 0.020 & -80 & & & & 1.00 & 0.30 & 0.15 \\
\hline
\end{tabular}

$\dagger$ Note that $\left[\alpha_{\mathrm{K} 3}, \alpha_{\mathrm{K} 5}\right]=[0.10,0.95],\left[\alpha_{\mathrm{D} 3}, \alpha_{\mathrm{D} 5}\right]=[0.15,0.95],\left[\alpha_{\mathrm{F} 3}, \alpha_{\mathrm{F} 5}\right]=[0.32,0.25]$ and zero for others.

Table 3 Summary of column experimental dataset ${ }^{\dagger}$.

\begin{tabular}{c|c|c|c|c|c|c|c|c|c}
\hline & $\begin{array}{c}f_{c} \\
(\mathrm{MPa})\end{array}$ & $\begin{array}{c}f_{y} \\
(\mathrm{MPa})\end{array}$ & $\begin{array}{c}f_{y v} \\
(\mathrm{MPa})\end{array}$ & $\rho_{l}$ & $\rho_{v}$ & $a / d$ & $s / d$ & $P /\left(f_{c} A_{g}\right)$ & $\begin{array}{c}v_{\text {exp }} / \sqrt{f_{c}} \\
(\sqrt{\mathrm{MPa}})\end{array}$ \\
\hline Minimum & 13.1 & 331 & 327 & 0.010 & 0.001 & 2.22 & 0.23 & 0.00 & 2.69 \\
\hline Maximum & 45.0 & 547 & 526 & 0.040 & 0.008 & 4.04 & 1.16 & 0.61 & 10.41 \\
\hline Mean & 27.6 & 419 & 398 & 0.025 & 0.002 & 3.15 & 0.67 & 0.18 & 5.34 \\
\hline COV & 0.28 & 0.15 & 0.12 & 0.30 & 0.72 & 0.18 & 0.40 & 0.70 & 0.32
\end{tabular}

$\dagger$ The specimens considered are SC3 [36], 372 and 373 [37], 2CLH18, 2SLH18, 2CMH18, 3CMD12, and 3SMD12 [38], A4 and C1 [39], U1 and U2 [40], BR-S1 [41], Specimen 1 and Specimen 4 [27], 114 and 115 [42], CUW [43], 205 and 234 [44], 40.033E and 25.033E [45], Specimen 3 and Specimen 4 [46], No1 and No3 [47], No6 and No7 [48], S1 [49], and CR96L-S0[50].

$\S$ Note that $\rho_{l}$ and $\rho_{v}$ are longitudinal and transverse reinforcement ratio, respectively and $v_{\mathrm{exp}}=V_{\mathrm{n}, \mathrm{exp}} / b d$. 
Table 4 Component modeling for frame models.

\begin{tabular}{l|l|l|l|l}
\hline Model no. & Description & Column & Beam & Joint \\
\hline Model 1 & rigid joint & flexure + bar-slip & flexure & rigid \\
\hline Model 2 & joint shear & flexure + bar-slip & flexure & shear \\
\hline Model 3 & joint shear/anchorage & flexure + bar-slip & flexure & shear + anchorage \\
\hline Model 4 & column shear & flexure + bar-slip + shear & flexure & rigid \\
\hline Model 5 & joint and column shear & flexure + bar-slip + shear & flexure & shear \\
\hline
\end{tabular}

Table 5 Modeling uncertainties.

\begin{tabular}{l|c|c|l}
\hline \multicolumn{1}{c|}{ Random variables } & Mean [7] & COV & \multicolumn{1}{c}{ Distribution [55] } \\
\hline$f_{c}(\mathrm{MPa})$ & 27.6 & $0.176[55]$ & Normal \\
\hline$f_{y}(\mathrm{MPa})$ & 462 & $0.080[55]$ & Lognormal \\
\hline$\zeta$ & 0.05 & $0.600[7]$ & Lognormal \\
\hline
\end{tabular}

Table 6 Capacity limit state model for maximum story drift (\%).

\begin{tabular}{l|c|c|c|c|c|c|c|c}
\hline \multirow{2}{*}{ Frame model } & \multicolumn{2}{|c|}{ Slight } & \multicolumn{2}{c|}{ Moderate } & \multicolumn{2}{c|}{ Extensive } & \multicolumn{2}{c}{ Complete } \\
\cline { 2 - 9 } & $S_{C}$ & $\beta_{C}$ & $S_{C}$ & $\beta_{C}$ & $S_{C}$ & $\beta_{C}$ & $S_{C}$ & $\beta_{C}$ \\
\hline Rigid joint response & 0.5 & 0.3 & 1.0 & 0.3 & 3.5 & 0.3 & 6.0 & 0.3 \\
\hline Column shear response & 0.5 & 0.3 & 1.0 & 0.3 & 2.0 & 0.3 & 4.5 & 0.3 \\
\hline Joint shear/anchorage response & 0.5 & 0.3 & 0.9 & 0.3 & 2.0 & 0.3 & 4.5 & 0.3 \\
\hline
\end{tabular}




\section{List of Figures}

Fig. 1. Analytical model of beam-column joint subassemblage.

Fig. 2. Envelope of joint shear stress-strain relationship.

Fig. 3. Comparison of computed and experimental joint shear strength.

Fig. 4. Experimental and model responses: for interior joints (a) PEER14 [31] and (b) J-OH [32], for exterior joint (c) Unit 6 [33], and for exterior joint with anchorage failure (d) Unit 1 [33].

Fig. 5. Experimental and model responses for the worst prediction (T1 [34]).

Fig. 6. Modeling shear-dominated column: (a) finite element model and (b) shear, flexure, and total response envelopes.

Fig. 7. Experimental and model responses: for flexure-shear failure (a) Specimen 1 [27] and (b) U2 [40], and for shear failure (c) Specimen [46] and (d) 4CR96L-S0 [50].

Fig. 8. Experimental and model responses for the worst prediction (2CLH18 [38]).

Fig. 9. Design information of 4-story non-ductile space frame [7].

Fig. 10. Analytical frame models: (a) rigid joint response (Model 1), (b) joint shear response without anchorage failure (Model 2), (c) joint shear response with anchorage failure (Model 3), (d) column shear response (Model 4), and (e) joint and column shear response (Model 5).

Fig. 11. Comparison of column shear-story drift responses for first-story interior column: (a) joint shear response (Model 2), (b) column shear response (Model 4), and (c) joint and column shear response (Model 5).

Fig. 12. Comparison of column shear-story drift response for first story exterior column: (a) joint shear response (Model 2) and (b) joint shear/anchorage response (Model 3).

Fig. 13. Maximum story drift distribution: (a) rigid joint response (Model 1), (b) joint shear response (Model 2), (c) joint shear/anchorage response (Model 3), (d) column shear response (Model 4), and (e) joint and column shear response (Model 5).

Fig. 14. PSDMs with different analytical frame models: (a) rigid joint response (Model 1), (b) joint shear response (Model 2), (c) joint shear response and anchorage failure (Model 3), (d) column shear response (Model 4), and (e) joint and column shear response (Model 5).

Fig. 15. PSDMs for maximum story drift demand along each story level: (a) rigid joint response (Model 1), (b) joint shear response (Model 2), and (c) column shear response (Model 4).

Fig. 16. PSDMs for maximum roof drift demand: (a) rigid joint response (Model 1) and (b) joint shear response (Model 2). 
Fig. 17. Comparison of fragility curves with different frame models: (a) extensive and (b) complete damage state.

Fig. 18. Median intensity measures of fragility curves with different frame models.

Fig. 19. Comparison of fragility curves with and without aleatoric uncertainty: (a) joint shear response model (Model 2) and (b) column shear response model (Model 4). 


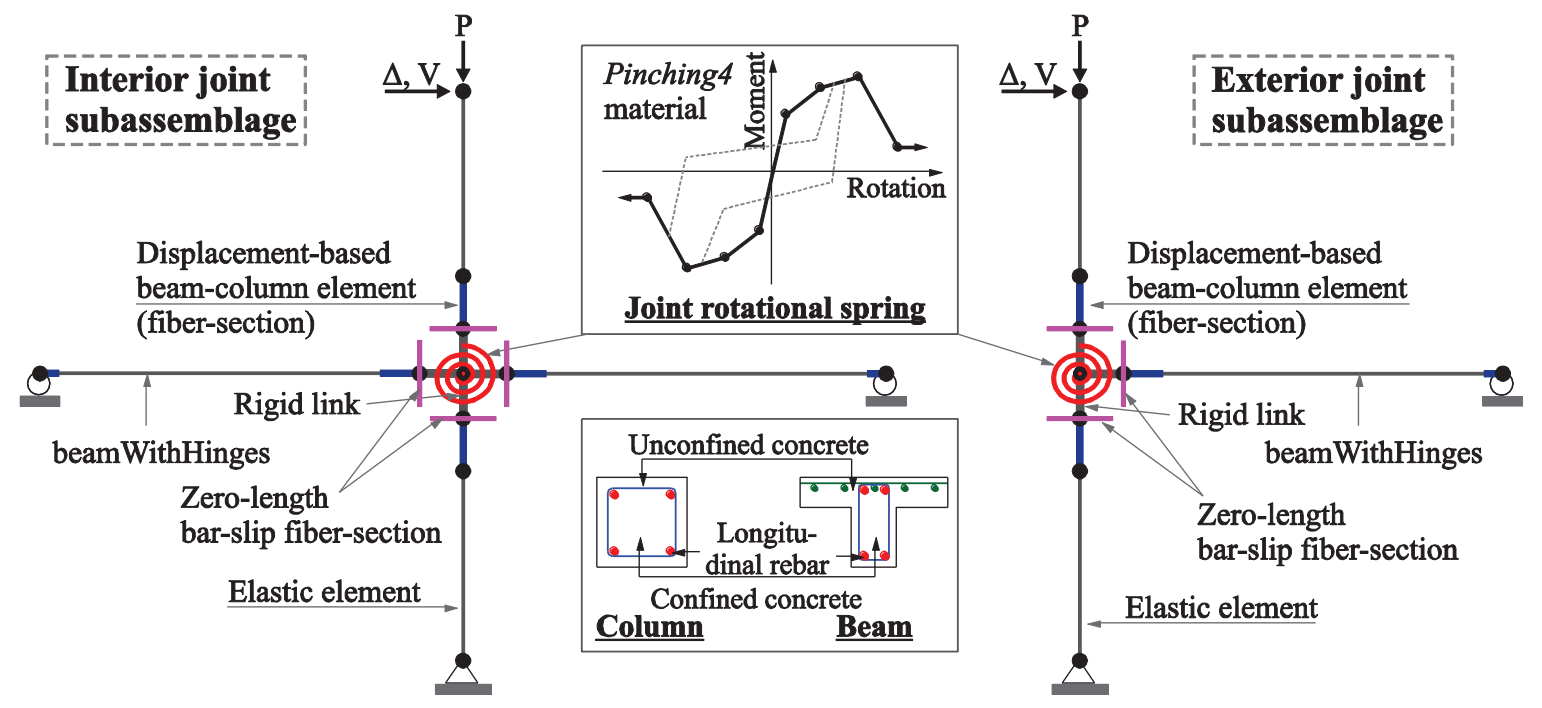

Fig. 1. Analytical model of beam-column joint subassemblage.

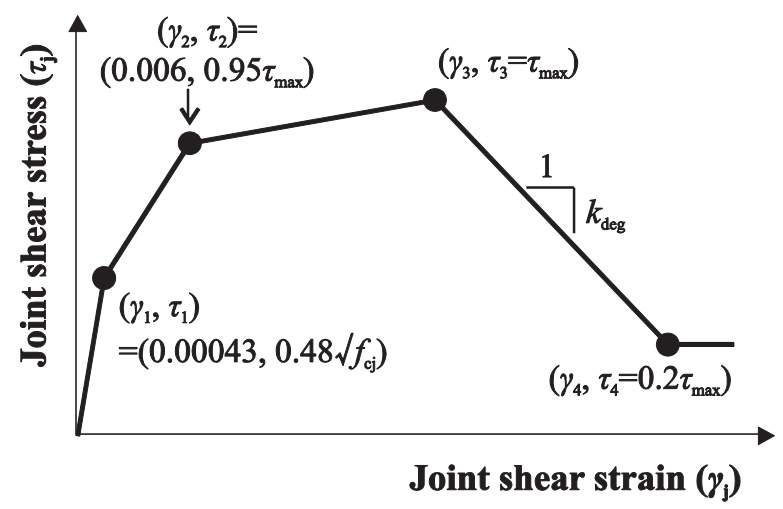

Fig. 2. Envelope of joint shear stress-strain relationship.

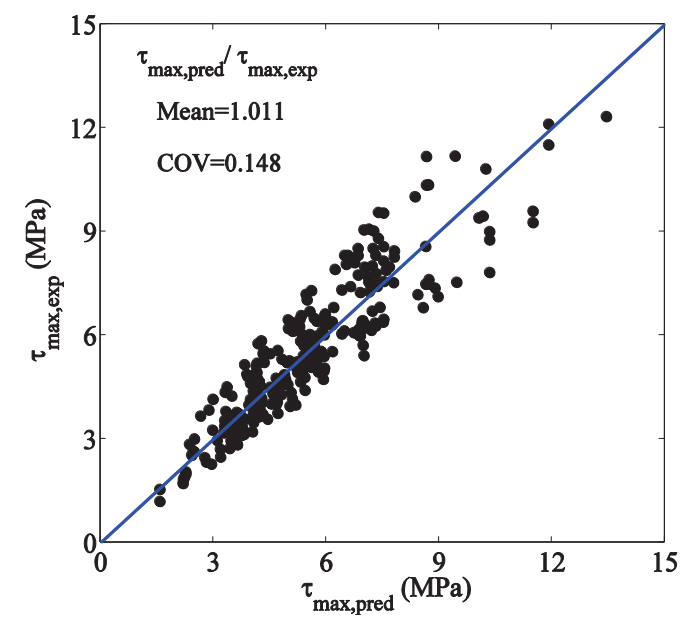

Fig. 3. Comparison of computed and experimental joint shear strength. 

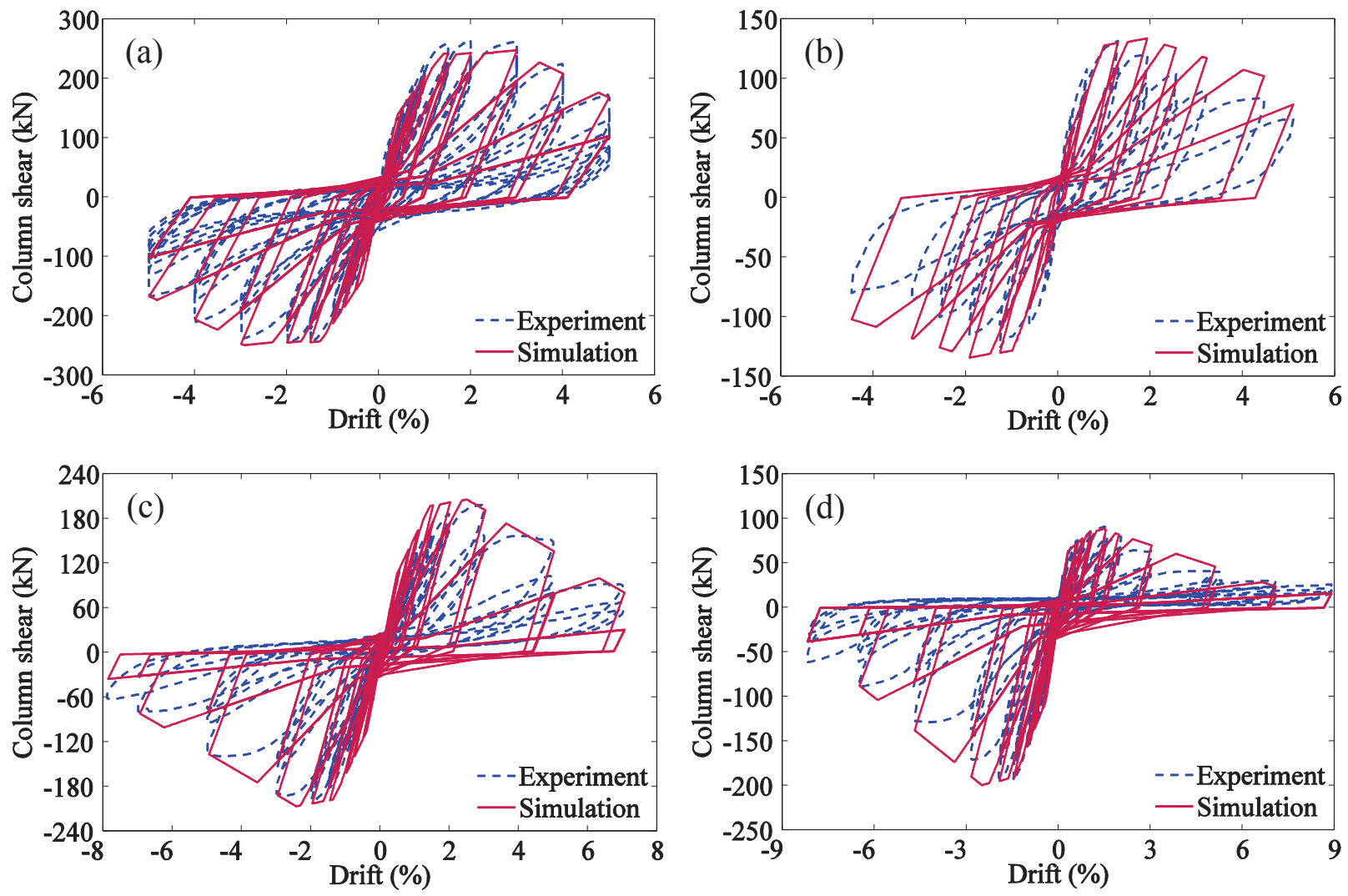

Fig. 4. Experimental and model responses for the best prediction: for interior joints (a) PEER14 [31] and (b) J-OH [32], for exterior joint (c) Unit 6 [33], and for exterior joint with anchorage failure (d) Unit 1 [33].

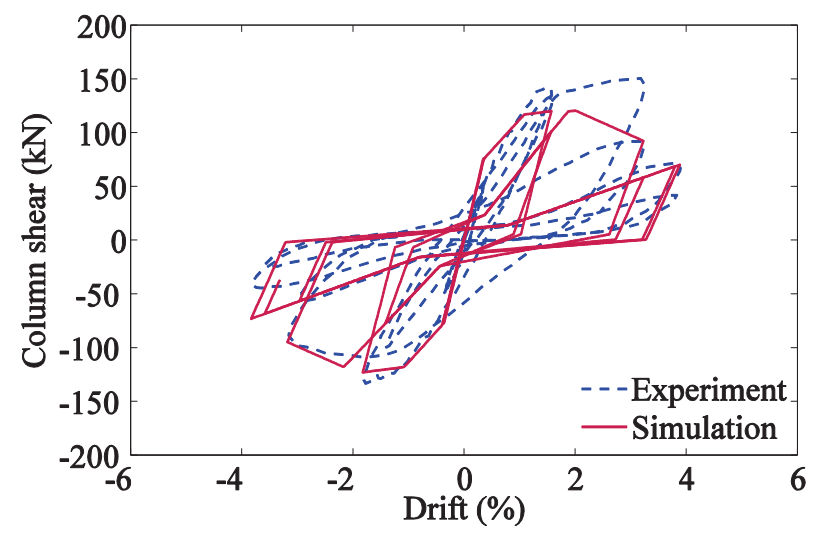

Fig. 5. Experimental and model responses for the worst prediction (T1 [34]). 


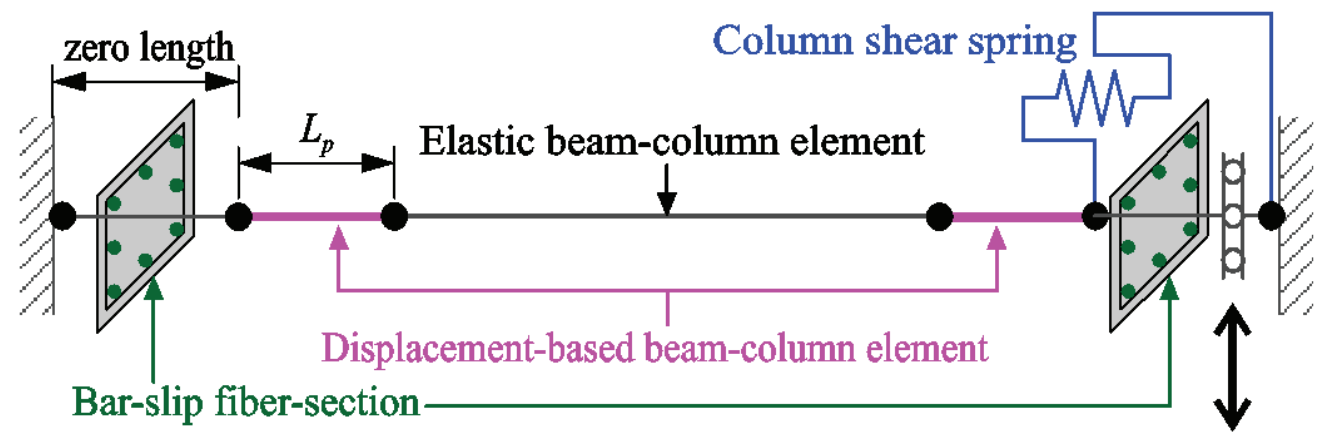

(a) Finite element model Applied loading

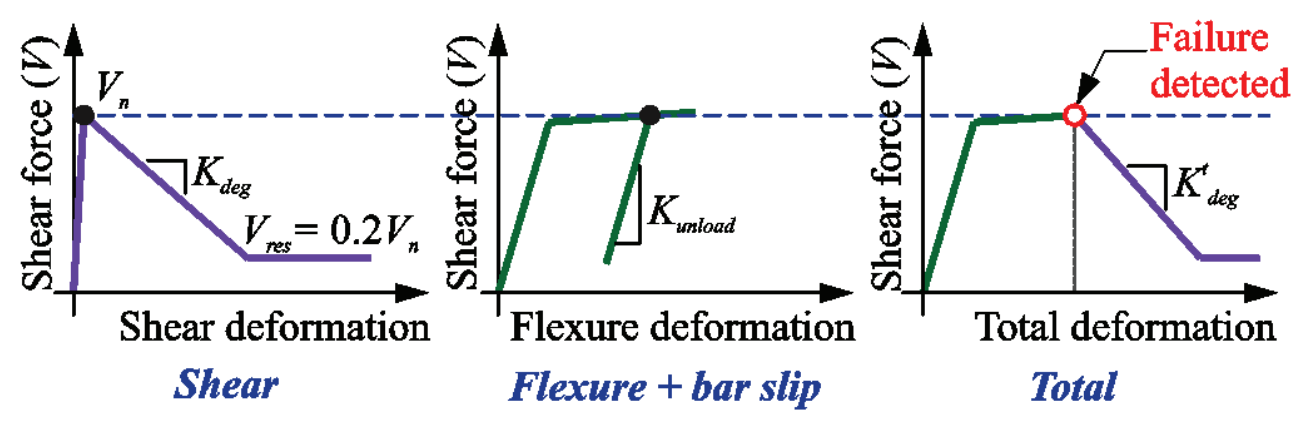

(b) Shear, flexure, and total response

Fig. 6. Modeling shear-dominated column: (a) finite element model and (b) shear, flexure, and total response envelopes. 

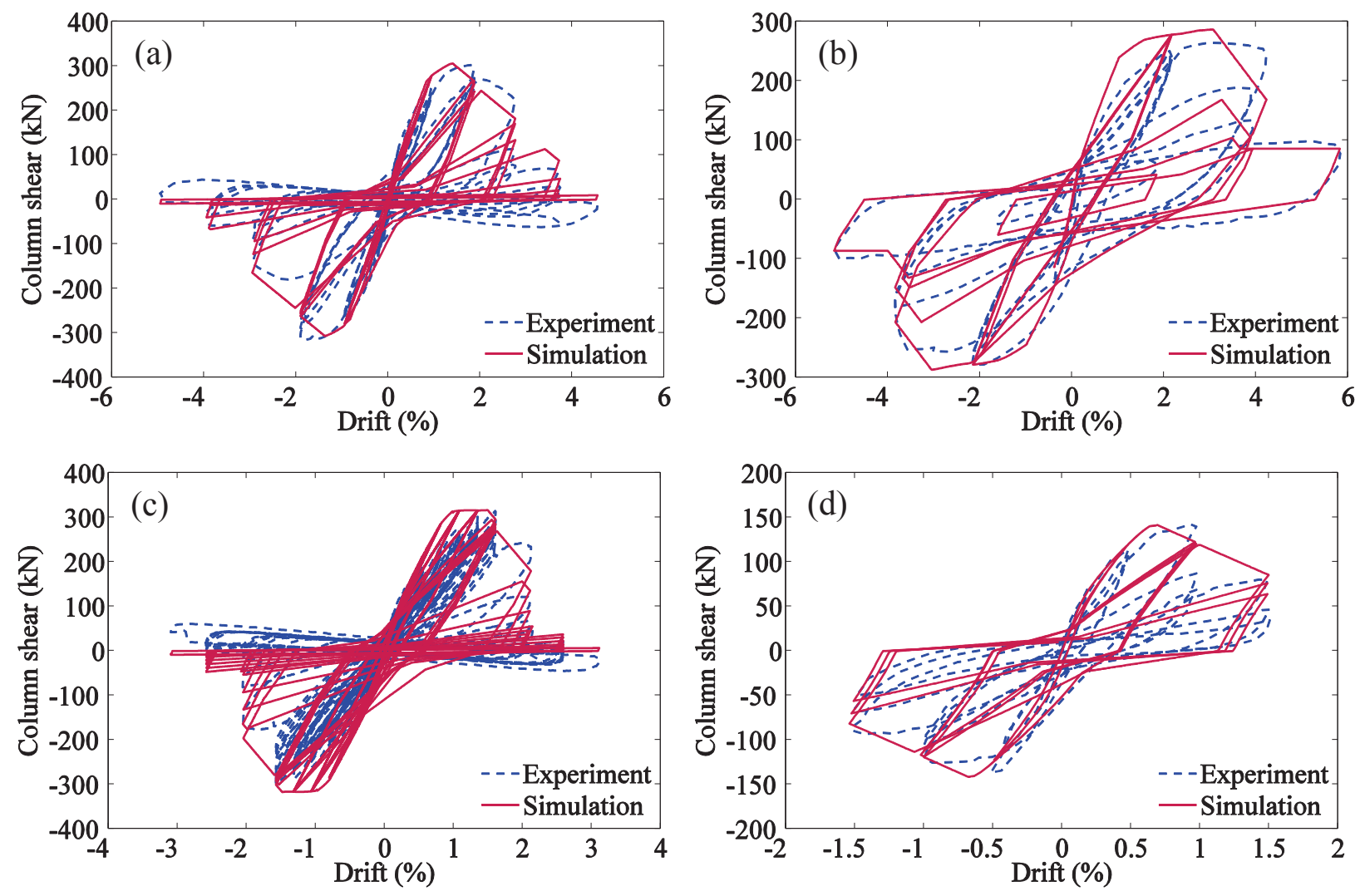

Fig. 7. Experimental and model responses: for flexure-shear failure (a) Specimen 1 [27] and (b) U2 [40], and for shear failure (c) Specimen 4 [46] and (d) CR96L-S0 [50].

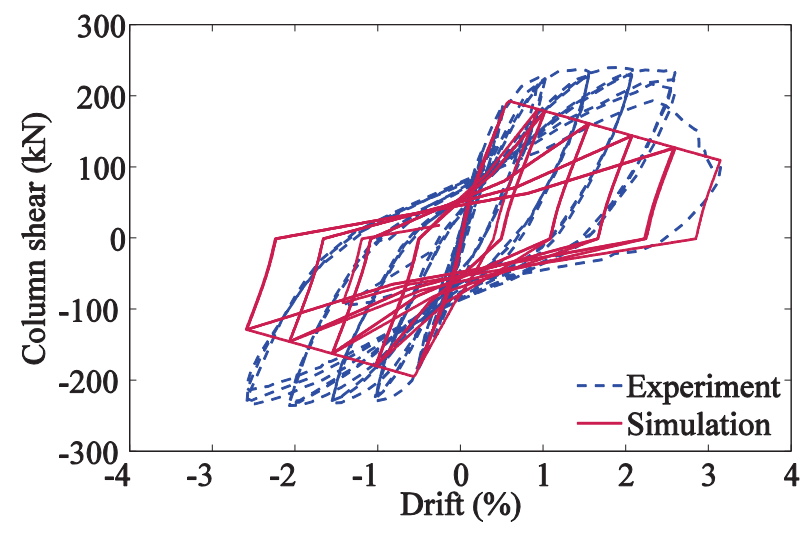

Fig. 8. Experimental and model responses for the worst prediction (2CLH18 [38]). 


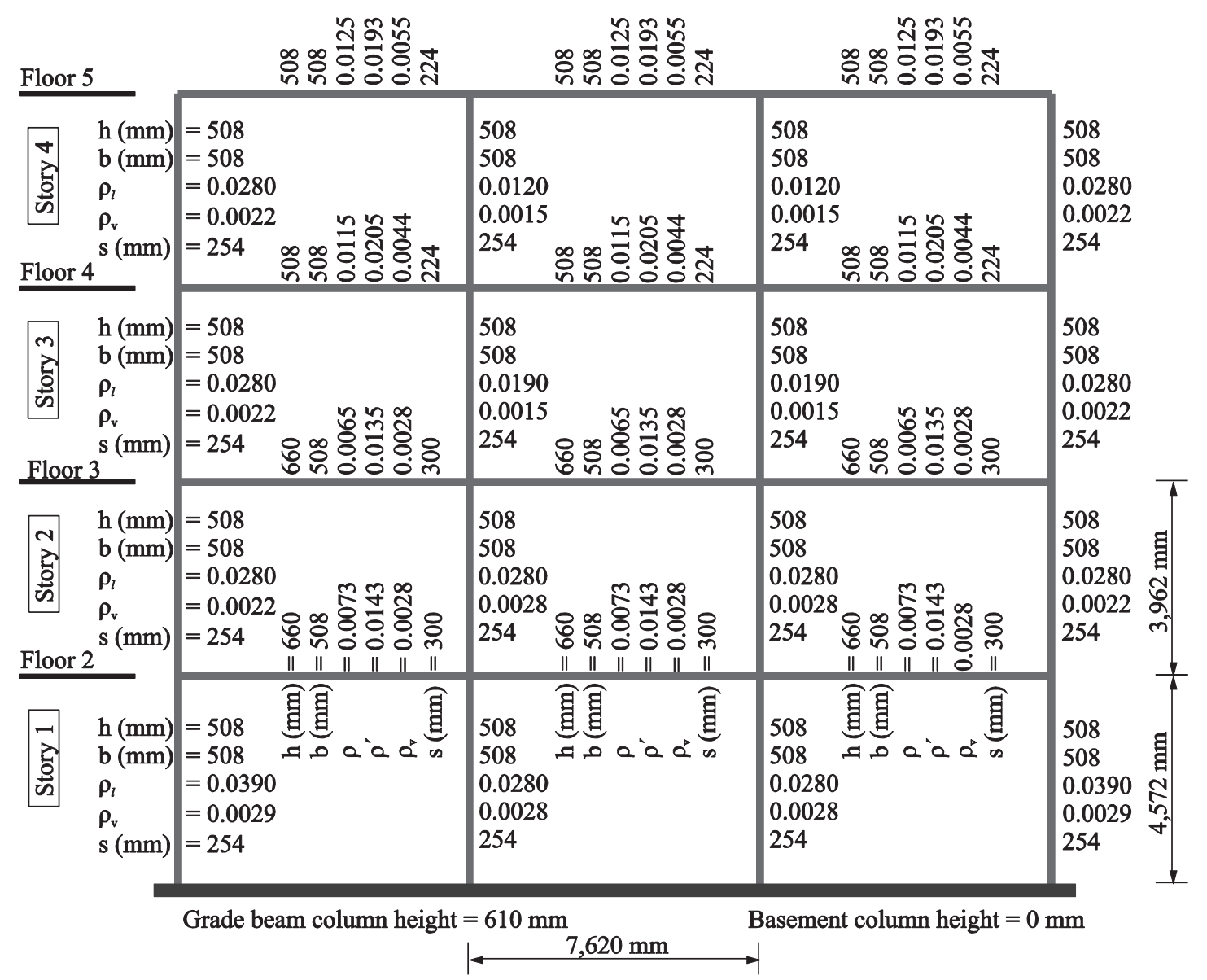

Fig. 9. Design information of 4-story non-ductile space frame [7].
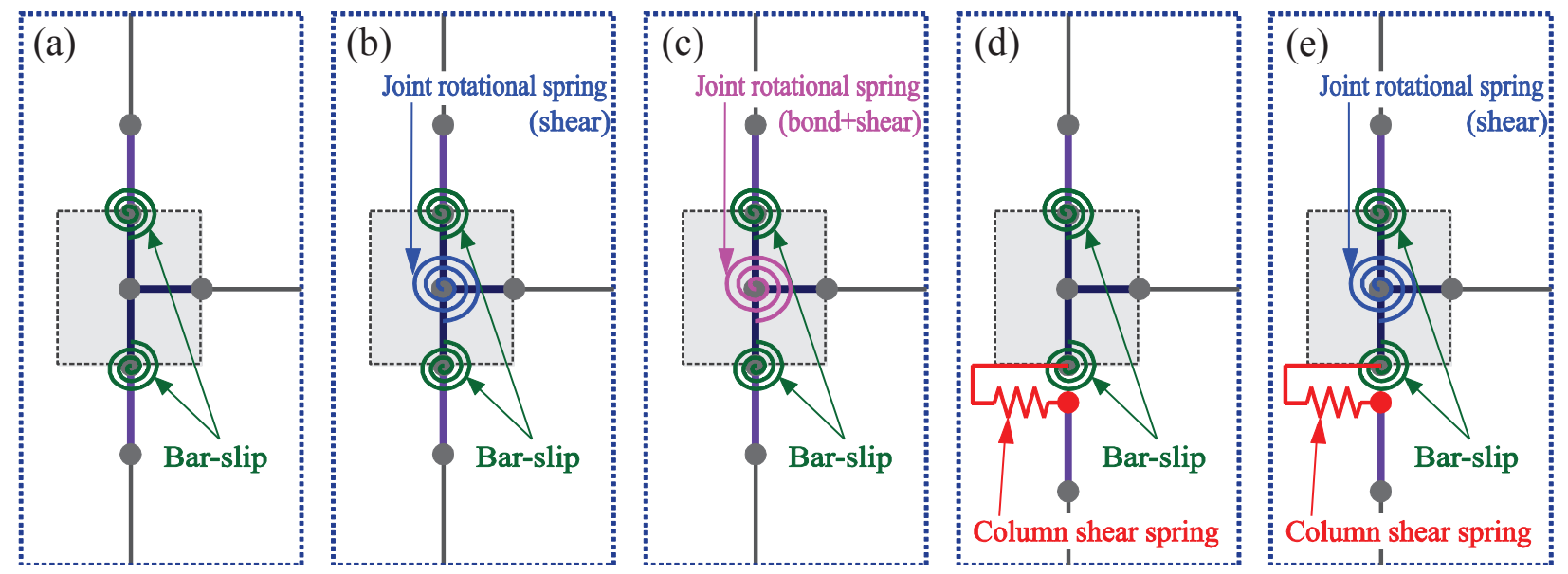

Fig. 10. Analytical frame models: (a) rigid joint response (Model 1), (b) joint shear response without anchorage failure (Model 2), (c) joint shear response with anchorage failure (Model 3), (d) column shear response (Model 4), and (e) joint and column shear response (Model 5). 

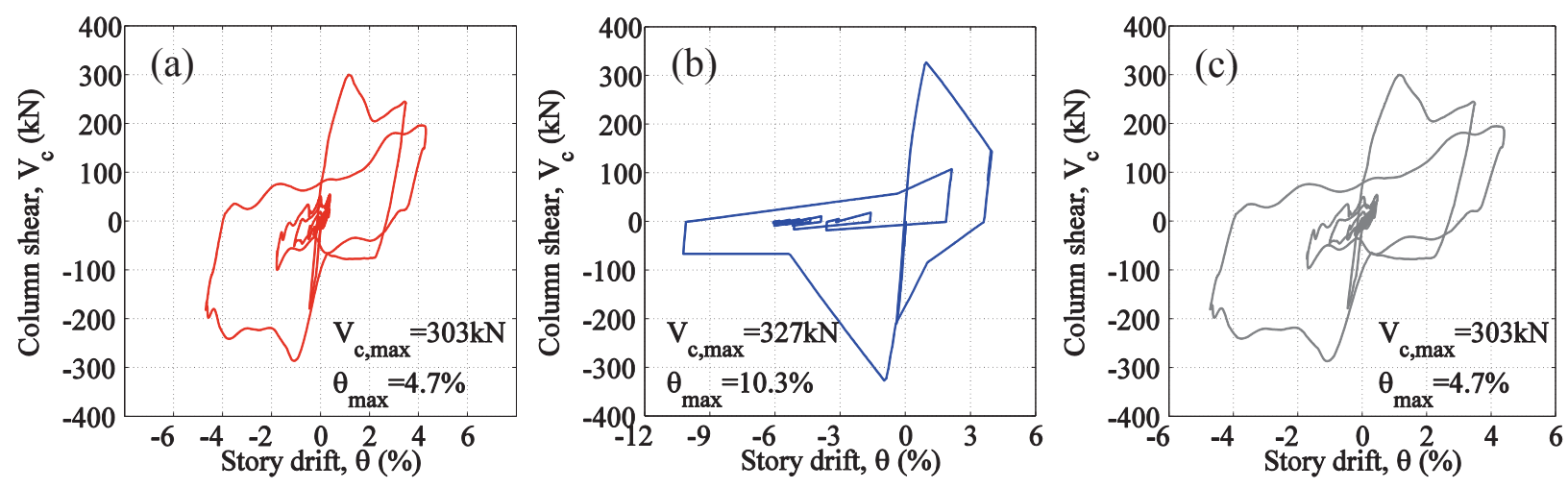

Fig. 11. Comparison of column shear-story drift responses for first-story interior column: (a) joint shear response (Model 2), (b) column shear response (Model 4), and (c) joint and column shear response (Model 5).
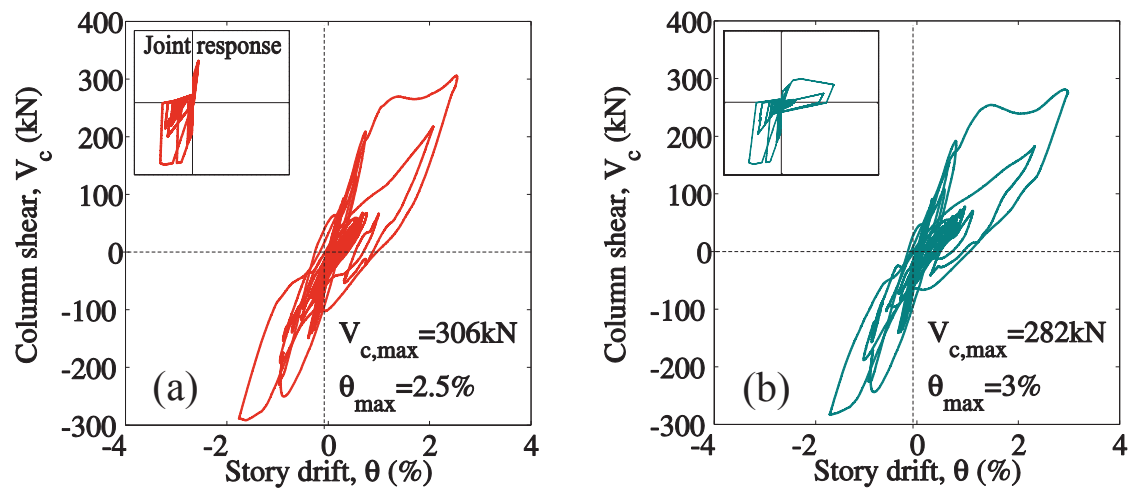

Fig. 12. Comparison of column shear-story drift response for first story exterior column: (a) joint shear response (Model 2) and (b) joint shear/anchorage response (Model 3). 

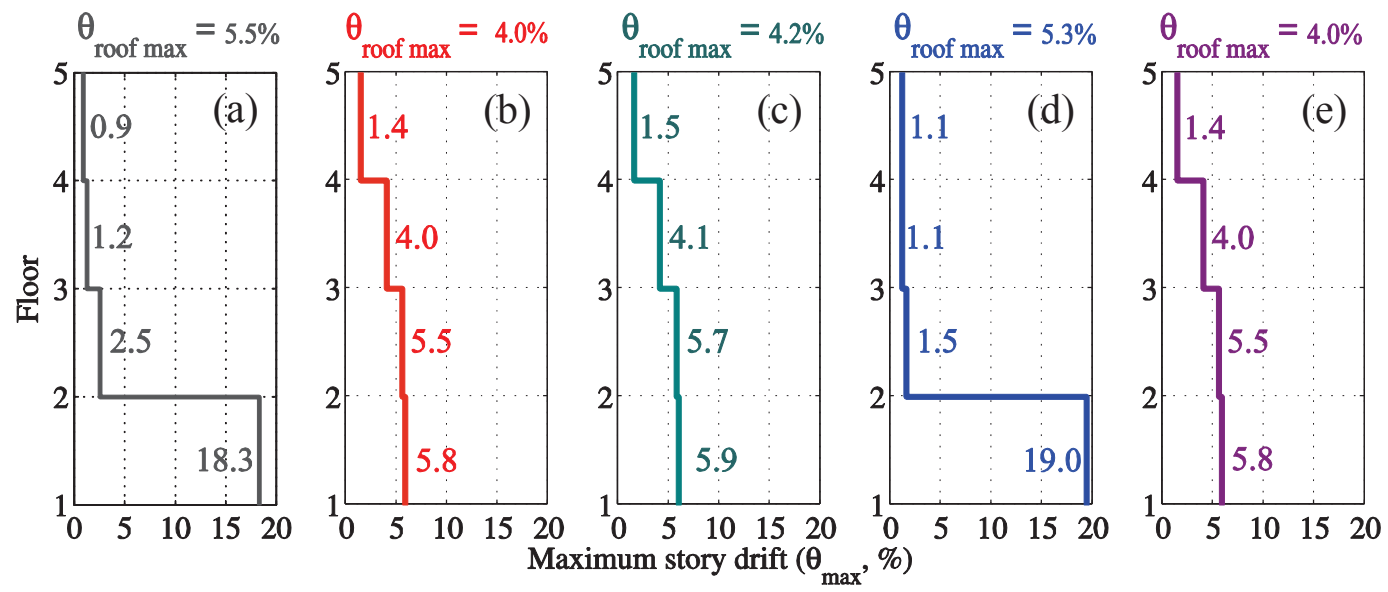

Fig. 13. Maximum story drift distribution: (a) rigid joint response (Model 1), (b) joint shear response (Model 2), (c) joint shear/anchorage response (Model 3), (d) column shear response (Model 4), and (e) joint and column shear response (Model 5). 

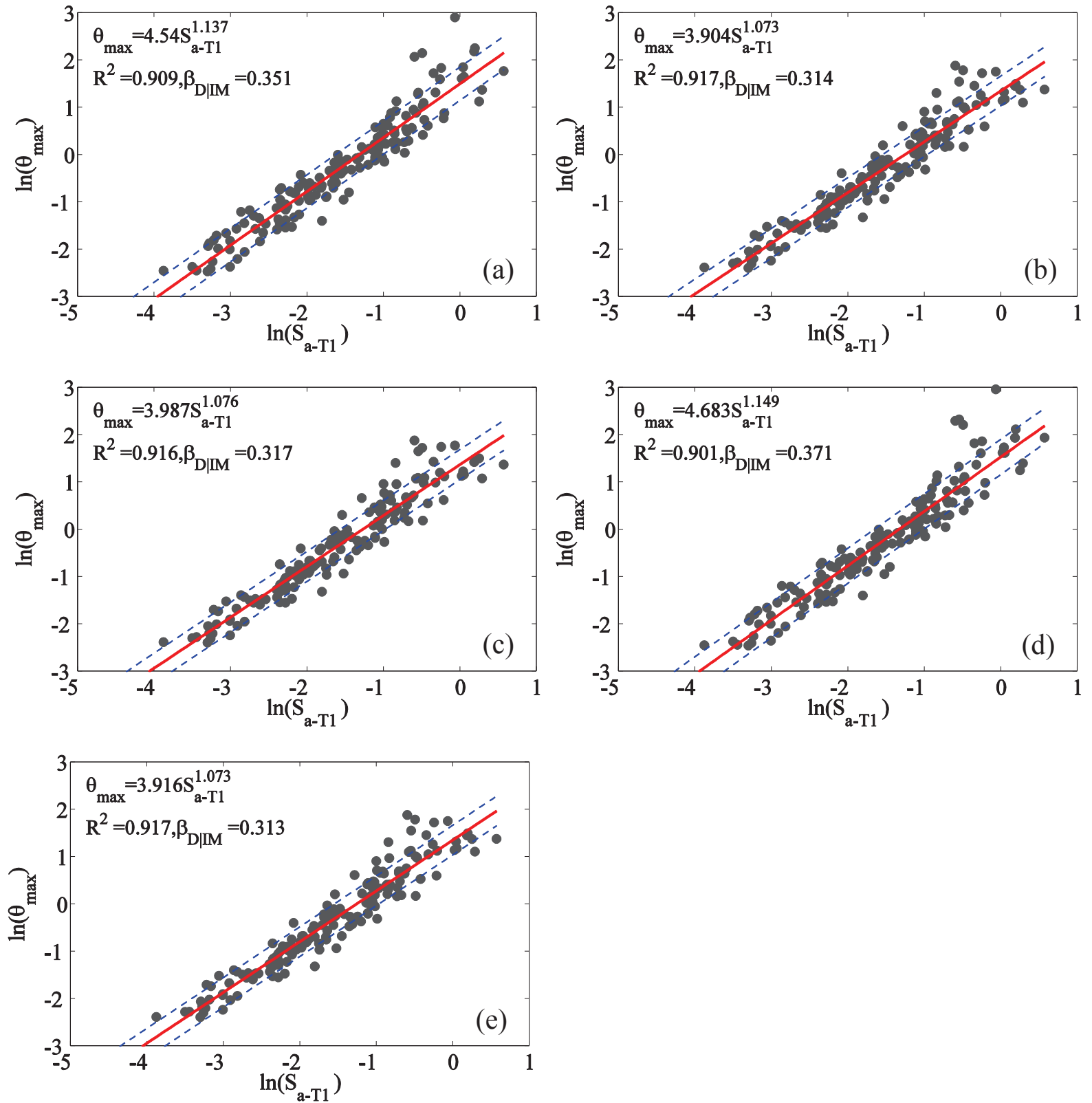

Fig. 14. PSDMs with different analytical frame models: (a) rigid joint response (Model 1), (b) joint shear response (Model 2), (c) joint shear response and anchorage failure (Model 3), (d) column shear response (Model 4), and (e) joint and column shear response (Model 5). 

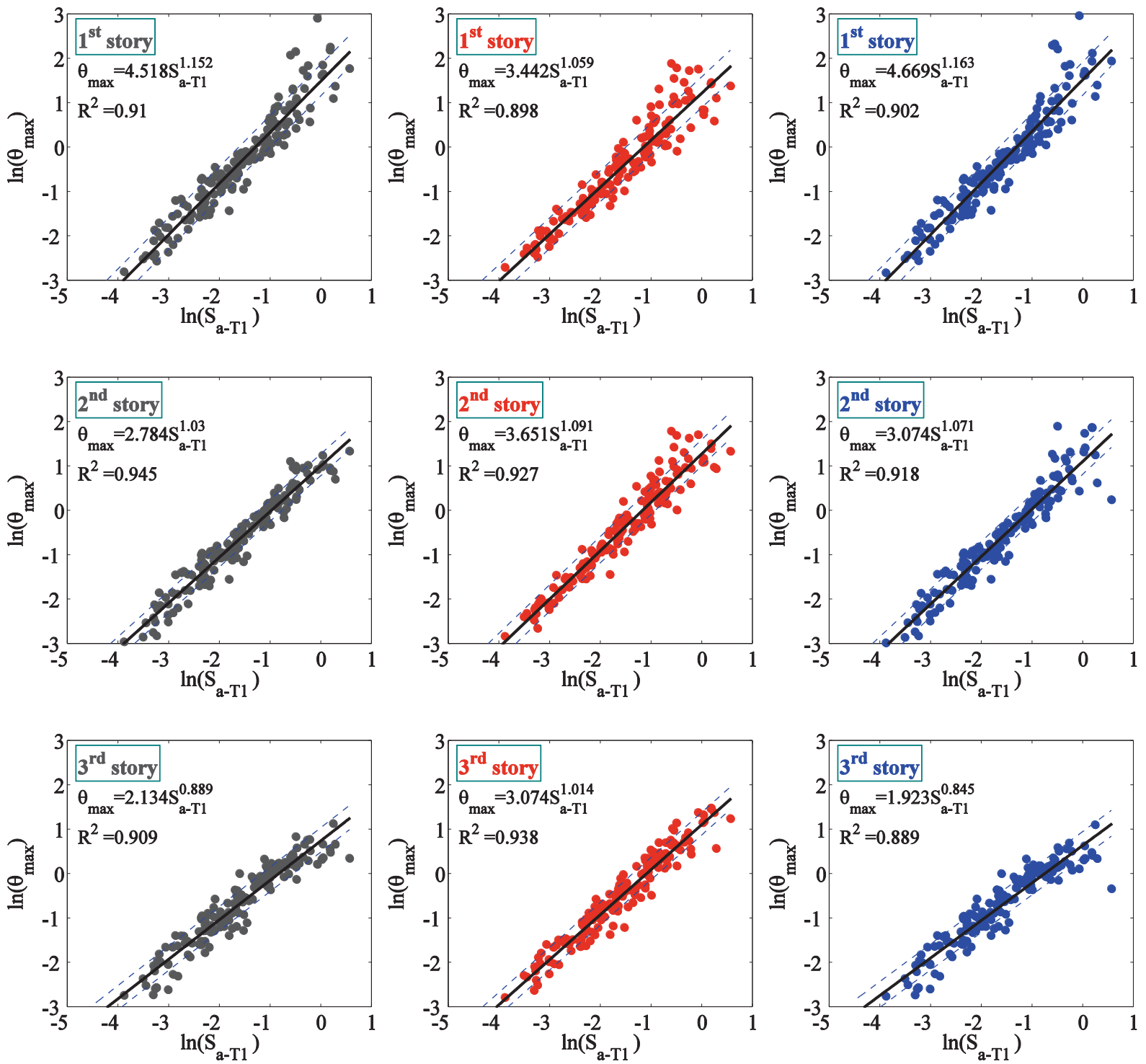

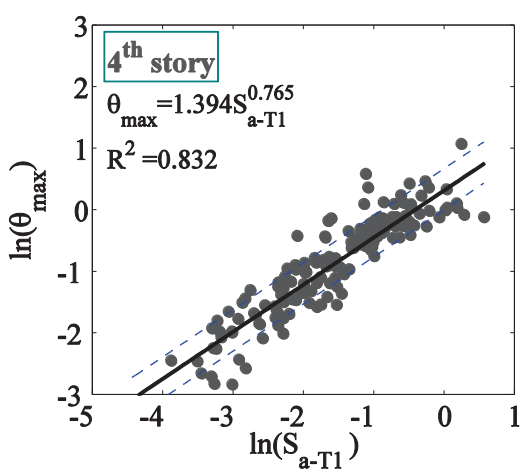

(a)

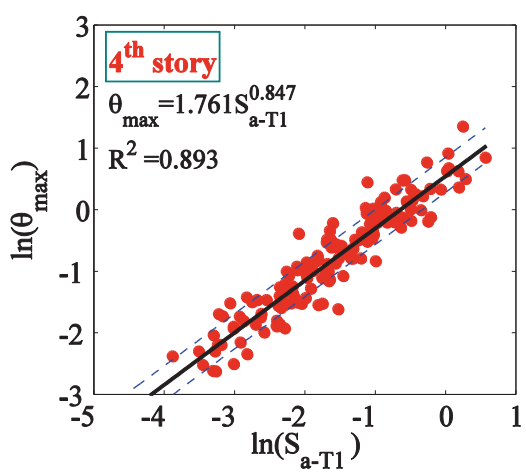

(b)

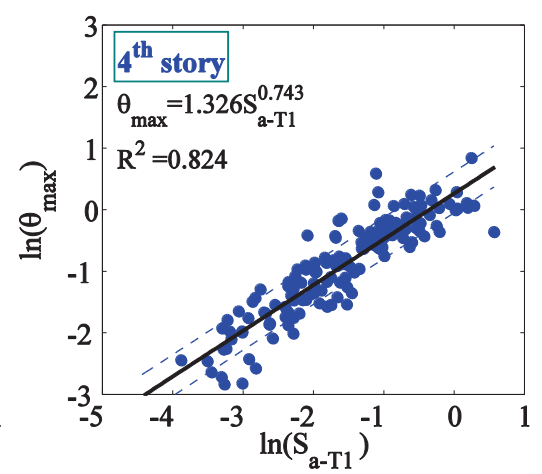

(c)

Fig. 15. PSDMs for maximum story drift demand along each story level: (a) rigid joint response (Model 1), (b) joint shear response (Model 2), and (c) column shear response (Model 4). 

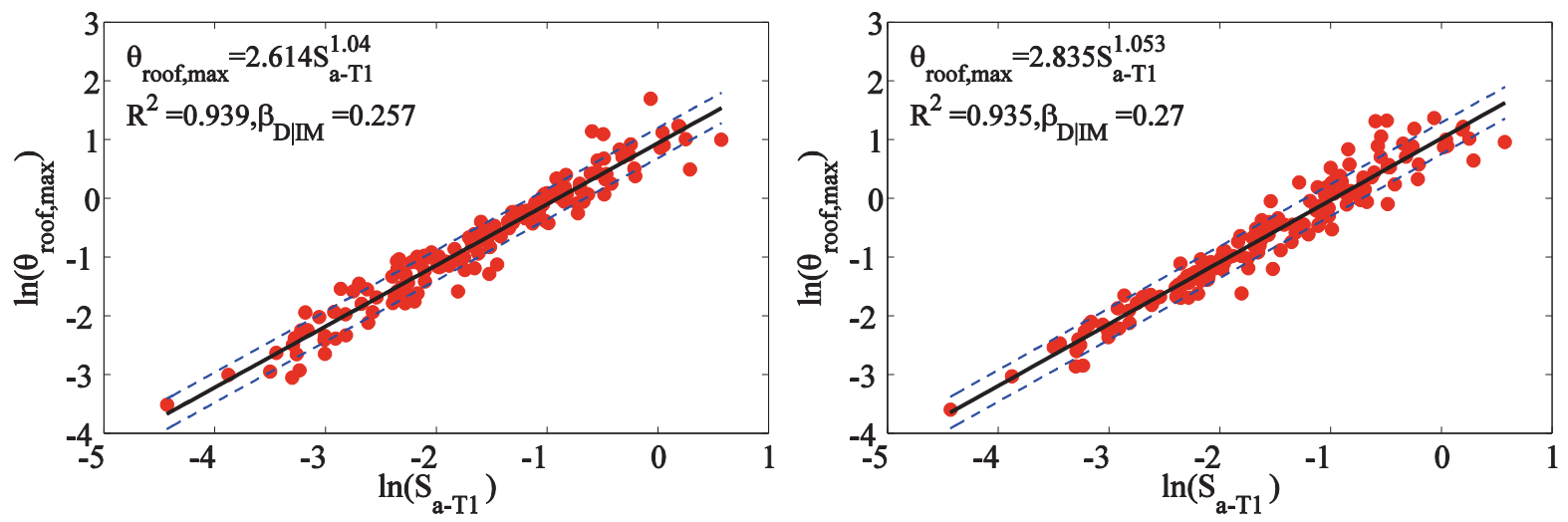

Fig. 16. PSDMs for maximum roof drift demand: (a) rigid joint response (Model 1) and (b) joint shear response (Model 2).
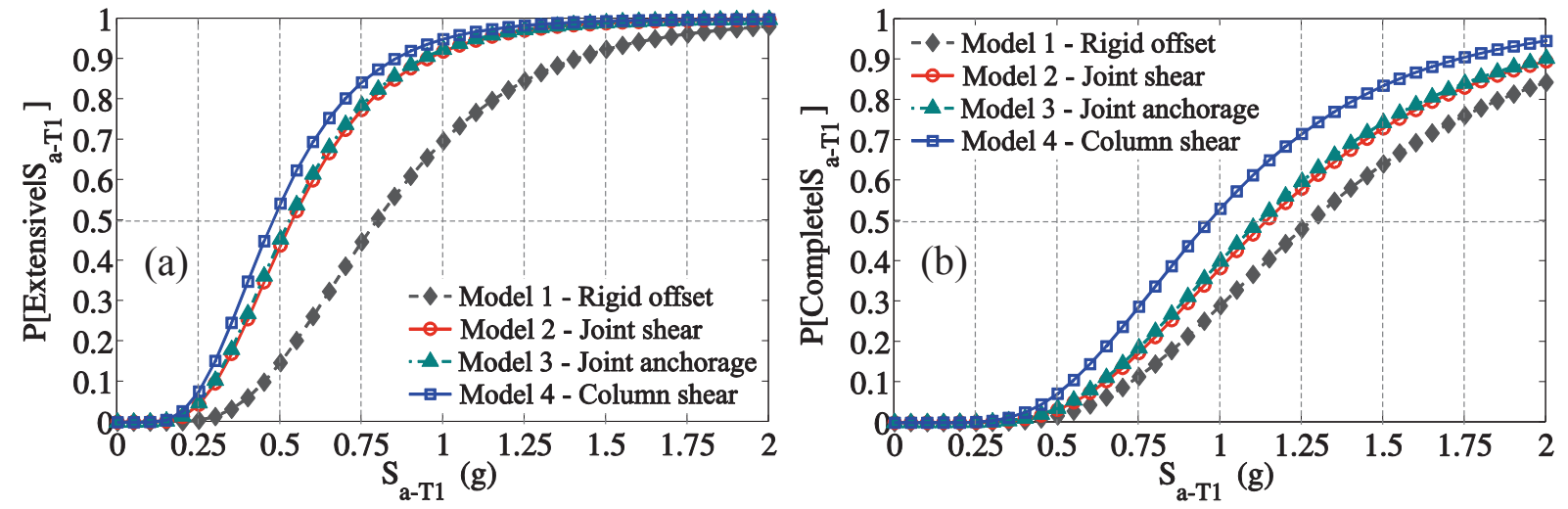

Fig. 17. Comparison of fragility curves with different frame models: (a) extensive and (b) complete damage state. 


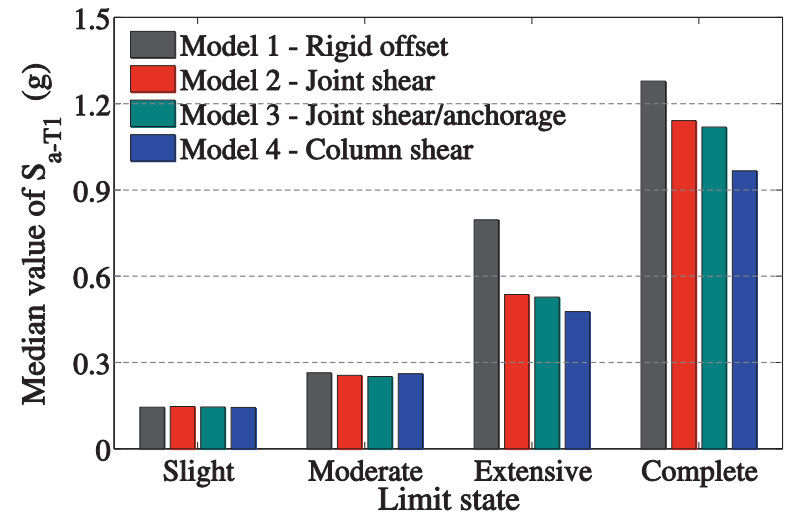

Fig. 18. Median intensity measures of fragility curves with different frame models.
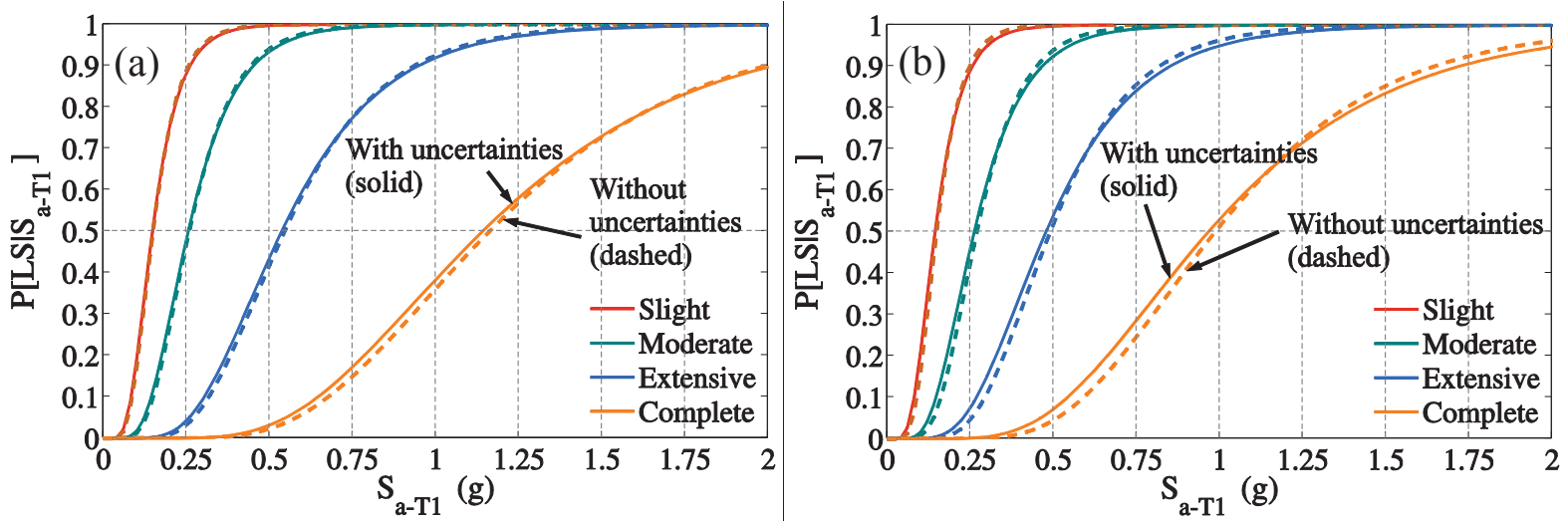

Fig. 19. Comparison of fragility curves with and without aleatoric uncertainty: (a) joint shear response model (Model 2) and (b) column shear response model (Model 4). 